\title{
Histochemical Visualization of Neutral Endopeptidase-24.11 (Enkephalinase) Activity in Rat Brain: Cellular Localization and Codistribution with Enkephalins in the Globus Pallidus
}

\author{
Stephen A. Back and Charles Gorenstein \\ Department of Pharmacology, University of California, Invine, Irvine, California 92717
}

\begin{abstract}
We have developed a novel fluorescent histochemical method to localize the enzyme neutral endopeptidase-24.11 (NEP, E.C. 3.4.24.11, enkephalinase) in the rat brain in order to directly compare the relative distributions of the enzyme and its putative peptide substrate, the enkephalins. The method is based on the sequential cleavage of the synthetic peptide substrate, glutaryl-alanyl-alanyl-phenylanyl-4-methoxy-2naphthylamide, by NEP and exogenous aminopeptidase $M$ to yield free 4-methoxy-2-naphthylamine (MNA). In the presence of nitrosalicylaldehyde, free MNA is captured, yielding an insoluble yellow fluorescent precipitate which marks the site of NEP activity. The specificity of the method was demonstrated using the selective NEP inhibitors thiorphan, phosphoramidon, and JHF26. All NEP staining throughout the brain was abolished using a 50-nM concentration of these inhibitors.
\end{abstract}

The enzyme was richly localized to many regions, including the cerebral cortex, caudate putamen, globus pallidus, hippocampus, substantia nigra, periaqueductal gray, several cranial nerve nuclei, and nuclei of the reticular formation of the medulla. In most regions, reaction product was associated with cell bodies of varying size and morphology. In a number of regions, colchicine increased the amount of NEP staining, particularly in cell processes. The regional distribution pattern of the enzyme, however, did not change in response to colchicine and was similar to that of untreated animals.

The histochemical localization of NEP was combined with fluorescent immunocytochemical visualization of the enkephalins in order to localize both in the same tissue section. In the globus pallidus, this combined fluorescent technique revealed numerous NEP-positive cell bodies surrounded by fiber pathways displaying intense enkephalin-like immunoreactivity. The source of the NEP in the globus pallidus was studied using the neurotoxic agent, $N$-methyl-D-aspartate

\footnotetext{
Received Mar. 9, 1989; revised June 12, 1989; accepted June 13, 1989.

This research was supported by NIDA grant DA03131 and predoctoral fellowship DA05255. S.A.B. is a recipient of a Pharmaceutical Manufacturers Association Foundation Medical Student Research Fellowship.

We would like to thank Drs. Christopher Evans, James Fallon, Chris Gall, Stewart Hendry, Frances Leslie, Sandra Loughlin, and Charles Ribak for many helpful discussions and suggestions. We are grateful to Kathy A. Gallardo and Marlene E. Hargreaves for their excellent technical assistance. JHF-26 was a generous gift from Dr. Bernard Roques.

This paper is dedicated to Dr. George B. Koelle on the occasion of his seventieth birthday. His contributions to histochemistry served as a source of inspiration for this work.

Correspondence should be addressed to Stephen Back at the above address.

Copyright (c) 1989 Society for Neuroscience $0270-6474 / 89 / 124439-17 \$ 02.00 / 0$
}

(NMDA). A pronounced decrease in NEP cellular staining was observed within $7 \mathrm{~d}$ in response to NMDA, persisted for at least 16 weeks, and correlated with injury of pallidal neurons. There was no apparent change in enkephalin-like immunoreactivity in the globus pallidus in response to NMDA. These data provide evidence that NEP and enkephalin in the globus pallidus derive from different sources. This study supports the hypothesis that NEP localizes to enkephalin-rich regions of the rat brain, and that the enzyme may be involved in the inactivation of synaptically released enkephalins.

Characterization of the enzymes involved in terminating the action of neuropeptides has been limited by the availability of suitable methods to determine the anatomical distribution of these enzymes in the nervous system. One exception is the enzyme neutral endopeptidase-24.11 (NEP, E.C. 3.4.24.11, enkephalinase), which is hypothesized to play a role in the physiological inactivation of the enkephalins and, perhaps, other neuropeptides (for review, see Hersh, 1982; McKelvy, 1986). A primary goal of the present study was to provide a direct means to visualize sites of NEP activity relative to sites of enkephalin-like immunoreactivity and determine whether the enzyme and peptide distributions are juxtaposed at the cellular level.

The enzyme NEP has been characterized in the kidney (Kerr and Kenny, 1974; Malfroy and Schwartz, 1982; Matsas et al., 1983; Almenoff and Orlowski, 1984) and the pituitary (Orlowski and Wilk, 1981) and shown to be homologous to enkephalinase, which is present in brain synaptic membrane fractions (Almenoff et al., 1981; Fulcher et al., 1982; Almenoff and Orlowski, 1984). NEP inactivates methionine- and leucine-enkephalin (tyrgly-gly-phe-met and tyr-gly-gly-phe-leu) by cleaving the gly-phe bond (Malfroy et al., 1978; Gorenstein and Snyder, 1980). A physiological role for NEP in the metabolic disposition of the enkephalins was supported by identification of radiolabeled tyrgly-gly as one of the primary degradation products of intracerebroventricularly (i.c.v.) administered tritiated-methionine-enkephalin (Craves et al., 1978). Further evidence to support a role for NEP in enkephalin degradation was obtained from several behavioral studies which observed a naloxone-reversible enhancement of analgesia in rats treated with metabolically stable enkephalin analogs and specific inhibitors of NEP (Roques et al., 1980; Fournie-Zaluski et al., 1983; Chipkin et al., 1988).

Although NEP was initially shown to metabolize the enkephalins and other opioid peptides (Malfroy et al., 1978; Gorenstein and Snyder, 1979, 1980; Hersh, 1984), it was subsequently shown to display a broad in vitro specificity for a variety of neuropep- 
tides, including substance $P$ (Matsas et al., 1983, 1985), neurokinin A (Hooper et al., 1985), bradykinin, neurotensin, oxytocin (Almenoff et al., 1981), cholecystokinin octapeptide (Zuzel et al., 1985), and interleukin- $\beta$ (Pierart et al., 1988). It is thus possible that the broad in vitro specificity displayed by NEP and other peptidases may be reflected in vivo as well (for review, see Hersh, 1982; Turner et al., 1985). Hence, although a peptidasemediated mechanism of inactivation of synaptically released peptides is regarded as the most likely means of terminating the action of neuropeptides, it is not known whether peptide-specific peptidases exist in brain.

Several studies have addressed the question of the specificity of NEP by examining the anatomical distribution of the enzyme relative to the enkephalins, substance $P$, or opiate receptors (Back and Gorenstein, 1985, 1989; Matsas et al., 1986; Waksman et al., 1986, 1987; Pollard et al., 1987a, b). These studies have found that the regional distribution of NEP in the CNS overlaps that of the enkephalins and the mu and delta opiate receptor subtypes. Owing to limitations of the immunocytochemical (Matsas et al., 1986) and autoradiographic methods (Waksman et al., 1986, 1987; Pollard et al., 1987a, b), the localization of NEP to cellular elements has not been achieved. We report here a new histochemical method to localize NEP, which enables direct visualization of the cell types associated with enzyme activity, and which also allows the distribution of NEP and the enkephalins to be directly compared in the same tissue section.

\section{Materials and Methods}

Histochemistry. Male Sprague-Dawley rats (8-12 weeks old) were used in all studies. Some animals, under rompum-ketamine general anesthesia, were injected stereotaxically (i.c.v.) with $250 \mu \mathrm{g}$ of colchicine (Sigma, St. Louis, MO) in $0.9 \%$ sodium chloride into the lateral cerebral ventricle. Sixteen hours later, the animals were deeply anesthetized with pentobarbital and perfused intracardially at a pressure of $100 \mathrm{~mm} \mathrm{Hg}$ with $0.9 \%$ sodium chloride at room temperature for $1.5 \mathrm{~min}$, followed by $400 \mathrm{ml}$ of $1.5 \%$ formaldehyde in $50 \mathrm{~mm}$ sodium phosphate buffer, $0.9 \%$ sodium chloride, $\mathrm{pH} 6.8$, for $25 \mathrm{~min}$, and a final 5 -min wash with saline. The National Institutes of Health guidelines for the care and use of laboratory animals were followed in these studies.

Brain regions were dissected and attached to a Vibratome stage with cyanoacrylate glue and were supported with a shell of low-gelling-temperature agarose (FMC Corporation, Rockland, ME). Thirty-five to fifty micron thick sections were cut with a Vibratome (Lancer). Free-floating sections were collected and stained for NEP activity in a solution of 50 $\mathrm{mm}$ Tris- $\mathrm{HCl}$, pH 7.4, containing $0.5 \mathrm{~mm}$ glutaryl-ala-ala-phe-4-methoxy-2-naphthylamide (GaapMNA; Enzyme Systems Products, Livermore, CA), 6 mm nitrosalicylaldehyde (NSA; Eastman-Kodak, Rochester, NY), and $20 \mu \mathrm{g} / \mathrm{ml}$ of endopeptidase-free aminopeptidase M(APM), prepared as described below. NSA was prepared as a $10 \%$ ethanol solution in $50 \mathrm{~mm}$ Tris- $\mathrm{HCl}$, pH 7.4. Tissue slices were continuously agitated during incubation at $37^{\circ} \mathrm{C}$ for about $1-3 \mathrm{hr}$, at $20^{\circ} \mathrm{C}$ for about $24 \mathrm{hr}$, or at $2-4^{\circ} \mathrm{C}$ for $1-3 \mathrm{~d}$. The reaction was terminated by rinsing the sections in cold $50 \mathrm{~mm}$ Tris- $\mathrm{HCl}, \mathrm{pH}$ 7.4. Sections were mounted on gelatin-coated glass slides and air-dried in the dark at room temperature. The sections were counterstained with a $1 \mu \mathrm{g} / \mathrm{ml}$ aqueous solution of ethidium bromide (Schmued et al., 1982) and coverslipped with spectroscopic grade glycerol diluted 1:6 with $50 \mathrm{~mm}$ phosphatebuffered saline, pH 6.8. Sections were stored in light-tight boxes under refrigeration to prolong the stability of the fluorescent precipitate. The NEP reaction product was photographed on a Leitz Dialux epifluorescence microscope using a wide-band violet (catecholamine) excitation filter (355-425 nm) or a wide-band blue (FITC) excitation filter (390$490 \mathrm{~nm}$ ). Ethidium bromide fluorescence was visualized with a narrowband green (rhodamine) excitation filter $(530-560 \mathrm{~nm})$. The distribution of NEP reaction product was verified using the atlas of the rat brain of Paxinos and Watson (1986).

Purification of aminopeptidase $M$. Commercially prepared APM (E.C.
3.4.11.2) is available as a crude ammonium sulfate fraction which has been found to be contaminated with an endopeptidase activity that, in in vitro assays for NEP, competes with NEP for GaapMNA (Orlowski and Wilk, 1981). Purification of APM was done as follows. A slurry of APM (Sigma, St. Louis, MO) (1.5-3 mg of protein) was dialyzed twice at $4^{\circ} \mathrm{C}$ against 2 liters of $1 \mathrm{~mm}$ phosphate buffer, $\mathrm{pH} 6.8$. The dialyzed enzyme (about $2-4 \mathrm{ml}$ ) was chromatographed at $4^{\circ} \mathrm{C}$ on a column $(1 \times$ $8 \mathrm{~cm}$ ) of Biogel HTP (BioRad, Richmond, CA) using a 100-ml linear gradient of 1-100 mM phosphate buffer, $\mathrm{pH} 6.8$, at a flow rate of 16$20 \mathrm{ml} / \mathrm{hr}$. Fractions $(2 \mathrm{ml})$ were collected at $4^{\circ} \mathrm{C}$. APM activity was detected by measuring the hydrolysis of leucyl-naphthylamide, and endopeptidase activity was measured using GaapMNA as substrate. The release of $\beta$-naph thylamine or 4-methoxy-2-naphthylamine (MNA) was measured colorimetrically following the addition of the azo dye fast blue B (Aldrich, Milwaukee, WI). Endopeptidase-free fractions containing APM were collected and dialyzed at $4^{\circ} \mathrm{C}$ against 1 liter of $50 \mathrm{~mm}$ Tris$\mathrm{HCl}$ buffer, $\mathrm{pH} 7.4$ for $18 \mathrm{hr}$. The dialyzed enzyme was concentrated about 12 -fold with an Amicon ultrafiltration apparatus (Lexington, MA) using a Diaflo ultrafiltration membrane $(25,000 \mathrm{Da}$ cutoff). The concentrated enzyme was stored at $4^{\circ} \mathrm{C}$ and was stable for more than 6 months.

Histochemical controls. The following controls were done to ensure that the localization of the histochemical reaction product specifically resulted from NEP-catalyzed cleavage of the substrate and did not result from cleavage of the substrate by other enzymes or from a nonspecific association of the reaction product with the tissue: (1) Sections were incubated in the histochemical solution from which either the substrate or the NSA was omitted; (2) sections were heated at $90^{\circ} \mathrm{C}$ for $5 \mathrm{~min}$ prior to histochemical staining to assess the heat sensitivity of the reaction; (3) sections were incubated in the histochemical solution containing 1 mM EDTA which chelates the zinc cofactor required for NEP activity; (4) sections were preincubated for $45 \mathrm{~min}$ at room temperature in the presence of $1 \times 10^{-9}$ to $1 \times 10^{-5} \mathrm{M}$ thiorphan, phosphoramidon or JHF-26, or $1 \times 10^{-9}$ to $3 \times 10^{-4} \mathrm{M}$ captopril and stained in the presence of the same respective concentration of inhibitor as in the preincubation; (5) a "postcoupling" staining reaction was done, in which either NSA or fast blue B was added at the end of the incubation, in order to assess the extent of diffusion of the MNA before it was trapped by the coupling agent; (6) APM was omitted from the histochemical solution and sections were incubated with GaapMNA or phe-MNA to determine whether MNA was produced via an endogenous aminopeptidase, acting on phe-MNA released from the parent substrate.

Lesion studies. Eleven animals were used for lesion studies in which $7.5,10$, or $20 \mu \mathrm{g}$ of $N$-methyl-D-aspartate (NMDA, $7.5 \mu \mathrm{g}$ in $0.25 \mu \mathrm{l}$ )

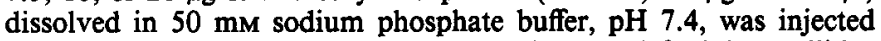
stereotaxically through a 26-gauge needle into the left globus pallidus at coordinates relative to the Bregma suture: A -0.8 , L 3.0, V 6.5 according to the atlas of Paxinos and Watson (1986). The injection rate was $0.1 \mu \mathrm{l} / \mathrm{min}$. After the injection, the needle was left in place for 5 min before it was slowly withdrawn. Animals were allowed to survive for $7,14,21,56$, or $112 \mathrm{~d}$ prior to death for NEP histochemistry as described above. The response to NMDA was assessed morphologically by Nissl stain or ethidium bromide fluorescent counterstain.

Enkephalin immunocytochemistry. Sections were processed for enkephalin immunocytochemistry at $4^{\circ} \mathrm{C}$ using a modification of the Coon's indirect immunofluorescent technique (Coons, 1958) or the peroxidaseantiperoxidase technique (Sternberger, 1979). Vibratome sections, prepared as described above for NEP histochemistry, were washed for 2 $\mathrm{hr}$ in a solution of $0.1 \mathrm{~m}$ lysine, $5 \%$ normal horse serum (NHS), and $0.1 \%$ triton $\mathrm{X}-100$ in $0.1 \mathrm{M}$ phosphate buffer, $\mathrm{pH} 7.4$. The sections were next incubated for $18 \mathrm{hr}$ in the primary mouse monoclonal antiserum to leu-enkephalin (Sera Labs, Crawley Down, Sussex) diluted 1:20 with $0.1 \mathrm{M}$ phosphate buffer, $\mathrm{pH} 7.4$, containing $2 \%$ NHS and $0.1 \%$ triton $\mathrm{X}-100$. Thereafter, the sections were washed for a total of $30 \mathrm{~min}$ in 2 changes of $0.1 \mathrm{M}$ phosphate buffer, $\mathrm{pH} 7.4$, containing $2 \%$ NHS and $0.1 \%$ triton $X-100$, followed by 2 more washes in the same buffer devoid of detergent. The sections were transferred to a biotinylated horse antimouse immunoglobulin ( $\mathrm{IGg}$ ) (Vector Laboratories, Burlingame, CA) diluted 1:100 in $0.1 \mathrm{~m}$ phosphate buffer, $\mathrm{pH} 7.4$, containing $2 \%$ NHS and $0.1 \%$ triton $X-100$, and incubated for $6 \mathrm{hr}$. The sections were washed for $30 \mathrm{~min}$, as described above, and transferred to fluorescein-conjugated avidin DCS (Vector Laboratories, Burlingame, CA) diluted 1:100 in 0.1 M sodium bicarbonate buffer, $\mathrm{pH} 8.2$, containing $2 \%$ NHS and $0.1 \%$ triton X-100, and incubated for $1 \mathrm{hr}$. Alternatively, the sections were processed for the peroxidase-antiperoxidase technique (Sternberger, 


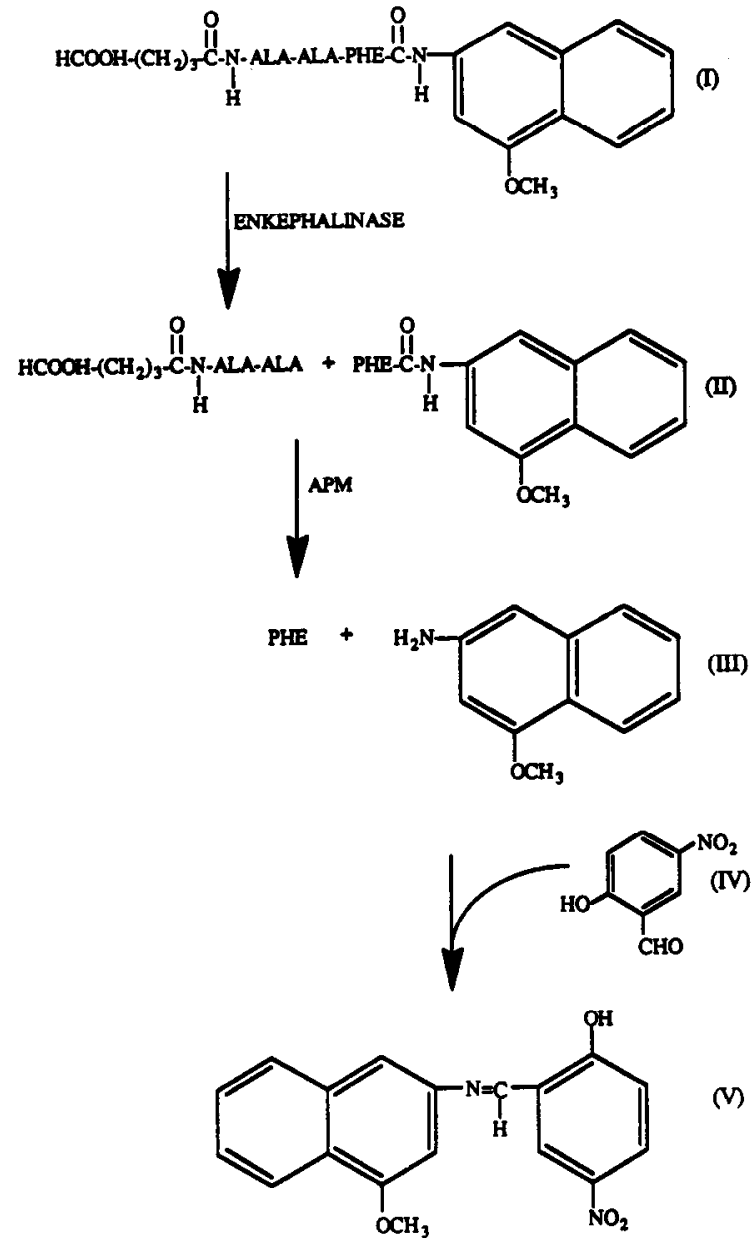

Figure 1. Schematic diagram of the fluorescent histochemical method for the localization of neutral endopeptidase-24.11. See text for details.

1979). Sections processed for the double fluorescence were washed in several changes of $0.1 \mathrm{M}$ bicarbonate buffer, $\mathrm{pH} 8.2$, for $30 \mathrm{~min}$, mounted onto gelatin-coated slides, and coverslipped with spectroscopic grade glycerol diluted 1:6 with $50 \mathrm{~mm}$ phosphate-buffered saline, pH 8.0.

In experiments conducted for combined histochemical/immunohistochemical staining, the enkephalin immunocytochemistry followed the NEP histochemistry. All procedures were conducted at $4^{\circ} \mathrm{C}$. The NEP and enkephalin fluorophores were covisualized using a wide-band blue (FITC) excitation filter $(390-490 \mathrm{~nm})$. The monoclonal antiserum to enkephalin displays no detectable cross-reactivity by radioimmunoassay with other opiate or nonopiate peptides, including $\beta$-endorphin and dynorphin 1-13.

\section{Results}

Figure 1 illustrates the fluorescent histochemical technique developed in this study to visualize sites containing NEP activity. NEP specifically cleaves the $\mathrm{N}$ - and C-terminal-blocked synthetic peptide substrate, GaapMNA (I), to generate phenylalanyl-4-methoxy-2-naphthylamide (II). Compound II is cleaved by exogenous APM to yield free MNA (III). Free MNA rapidly reacts with NSA (IV) to yield an insoluble yellow fluorescent precipitate ( $V$ ) marking the sites of NEP activity.

We found NEP activity to be completely inhibited by fixation with a formaldehyde concentration greater than $2 \%$. When sections of rat brain were incubated in the histochemical solution containing GaapMNA and NSA, 2 types of fluorophores were observed. When sections were viewed using a wide-band violet filter setting, a diffuse blue-green noncrystalline fluorescence was observed, particularly in white matter, in addition to the autofluorescence normally observed in sections not treated for histochemistry. This blue-green fluorescence persisted throughout the tissue sections following all histochemical control experiments (see Materials and Methods) and appeared to be a form of nonspecific fluorescence. It probably resulted from the nonenzymatic reaction of NSA with amino groups in tissue to form Schiff-base adducts (Dolbeare and Smith, 1977).

A second type of bright yellow fluorescent reaction product was observed, which consisted of small, discrete, punctate crystals. The appearance of the reaction product was similar to that previously described by Dolbeare and Smith (1977) for reaction of NSA with MNA. In all histochemical control studies, the yellow fluorescent precipitate disappeared completely. These control experiments verified that this fluorescent precipitate was the result of enzymatic hydrolysis of GaapMNA. Little staining was observed when GaapMNA was incubated without exogenous APM, indicating that almost all the phe-MNA produced in the histochemical assay (see Fig. 1) was generated by exogenous APM. As previously observed (Dolbeare and Smith, 1977), the size and appearance of the MNA-NSA adduct changed with prolonged incubation times. Typically, once a small nucleus of reaction product appeared in the tissue, it continued to grow to form larger crystalline aggregates consisting of a stellate array of needle-like crystals which often pierced through cells or processes, obscuring the site from which the crystals originated. By reducing the temperature of the incubation to $20^{\circ} \mathrm{C}$ or $4^{\circ} \mathrm{C}$, it was possible to obtain a discrete reaction product that permitted visualization of cell bodies and their associated processes.

The specificity of this method for NEP localization is shown in Figure 2, which demonstrates the effect of various enzyme inhibitors on the production of histochemical reaction product in the ventral caudate putamen (see Fig. $2 A$ ). Figure $2 B$ shows the typical distribution of reaction product seen in an untreated tissue section. The reaction product appears to localize primarily to the gray matter surrounding the axon bundles of the internal capsule. Despite a prolonged staining period $\left(48 \mathrm{hr}\right.$ at $\left.4^{\circ} \mathrm{C}\right)$, all staining seen in the CNS was blocked in the presence of a 50nM concentration of a single NEP inhibitor, thiorphan (Fig. 2C) or phosphoramidon (Fig. 2D). The more potent bidentate NEP inhibitor JHF-26 blocked all staining at a concentration as low as $10 \mathrm{nM}$ (data not shown). The chelating agent EDTA (1 mM) also inhibited all staining in the CNS (not shown). By contrast, tissue stained in the presence of $300 \mu \mathrm{M}$ captopril (Fig. 2E), an angiotensin-converting enzyme inhibitor (Cushman et al., 1977), did not differ from untreated tissue (Fig. $2 B$ ).

Figure $3 A$ shows a higher-power photomicrograph of the histochemical staining in the caudate putamen which is representative of the region shown in Figure $2 A$. At this magnification, the NEP reaction product was found to be discretely localized within the tissue (arrows). When this same section was viewed using a narrow-band green filter to visualize ethidium bromide counterstained cell bodies (Fig. $3 B$ ), it was found that the histochemical reaction product codistributed with the profiles of numerous cell bodies. The discrete distribution and low background staining indicated that the MNA was rapidly captured by the NSA and did not diffuse from the site of its enzymatic production.

Given that commercially available APM is often contaminated by a soluble endopeptidase activity that degrades GaapMNA (Orlowski and Wilk, 1981), APM was purified as 


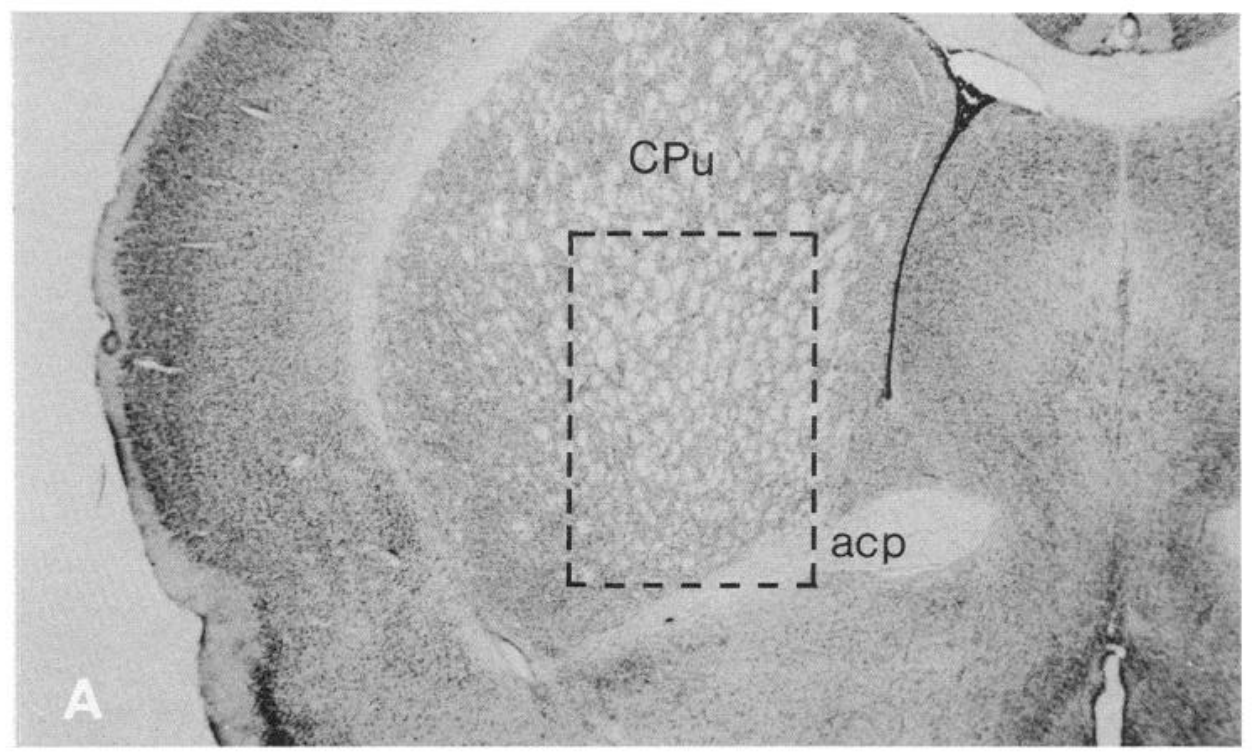

Figure 2. Low-power fluorescent photomicrographs $(B-E)$ of coronal sections of the rat ventral caudate putamen demonstrating the specificity of the histochemical method for NEP localization. $A$, Low-power light photomicrograph of a coronal section of rat brain at the level of the anterior commissure, posterior $(a c p)$, stained with cresyl violet and intended for orientation in $B$ $E$, below. The boxed area contains the approximate region of the caudate putamen $(C P u)$ shown in $B-E$. The paler structures in the caudate putamen are myelinated axon bundles of the internal capsule. The appearance of these axon bundles in the fluorescent photomicrographs $(B-E$, below) is indicated by $a r$ rows. $B$, Typical distribution pattern of NEP reaction product in an untreated tissue section. $C, D$, Absence of NEP reaction product in tissue incubated in histochemical staining solution containing $50 \mathrm{~nm}$ thiorphan $(C)$ or $50 \mathrm{~nm}$ phosphoramidon $(D) . E$, Appearance and distribution of NEP reaction product observed in tissue incubated in the presence of captopril $(300 \mu \mathrm{M})$ does not differ from untreated tissue $(A)$. Scale
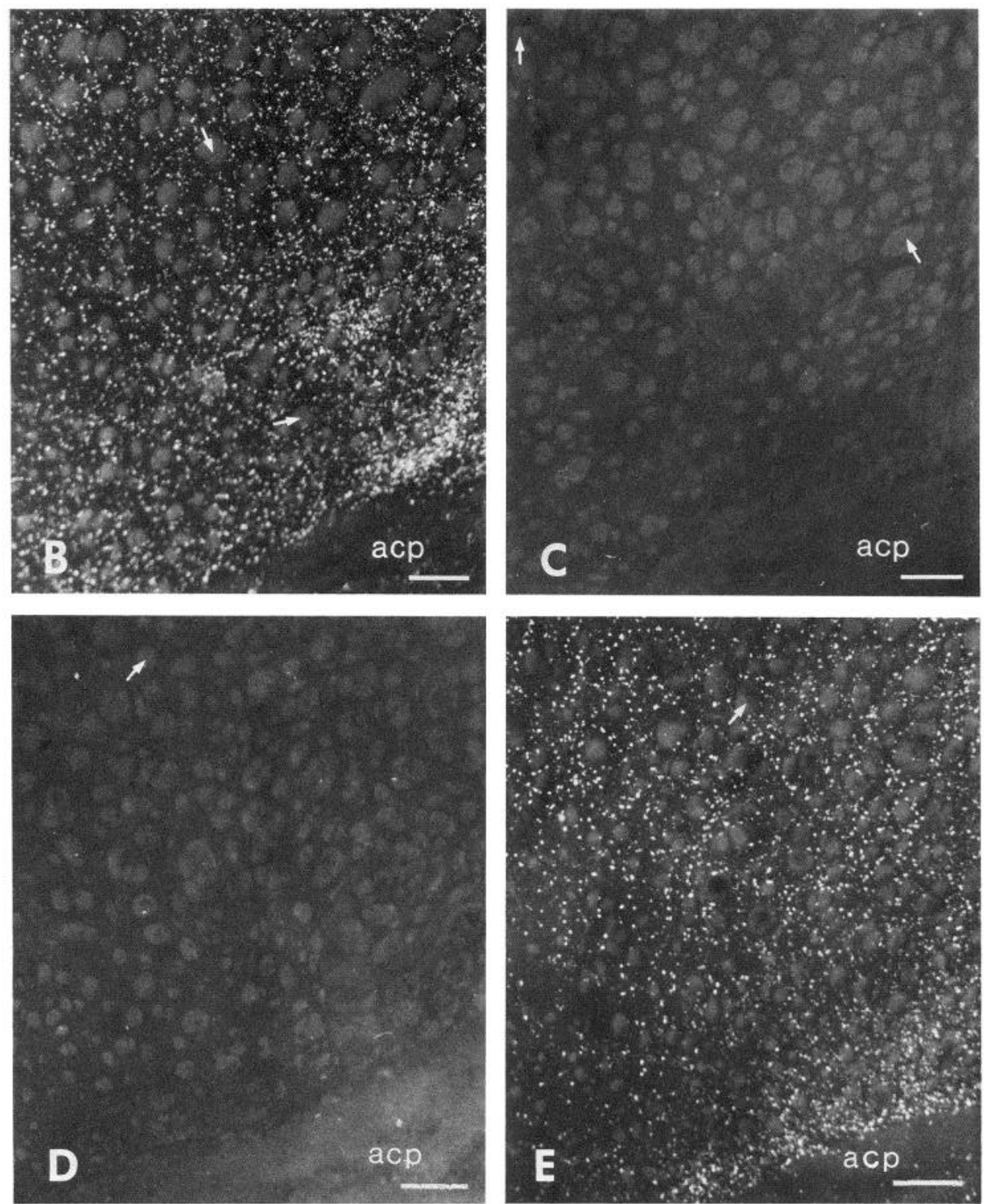
bar, $250 \mu \mathrm{m}$ in $B-E$. 

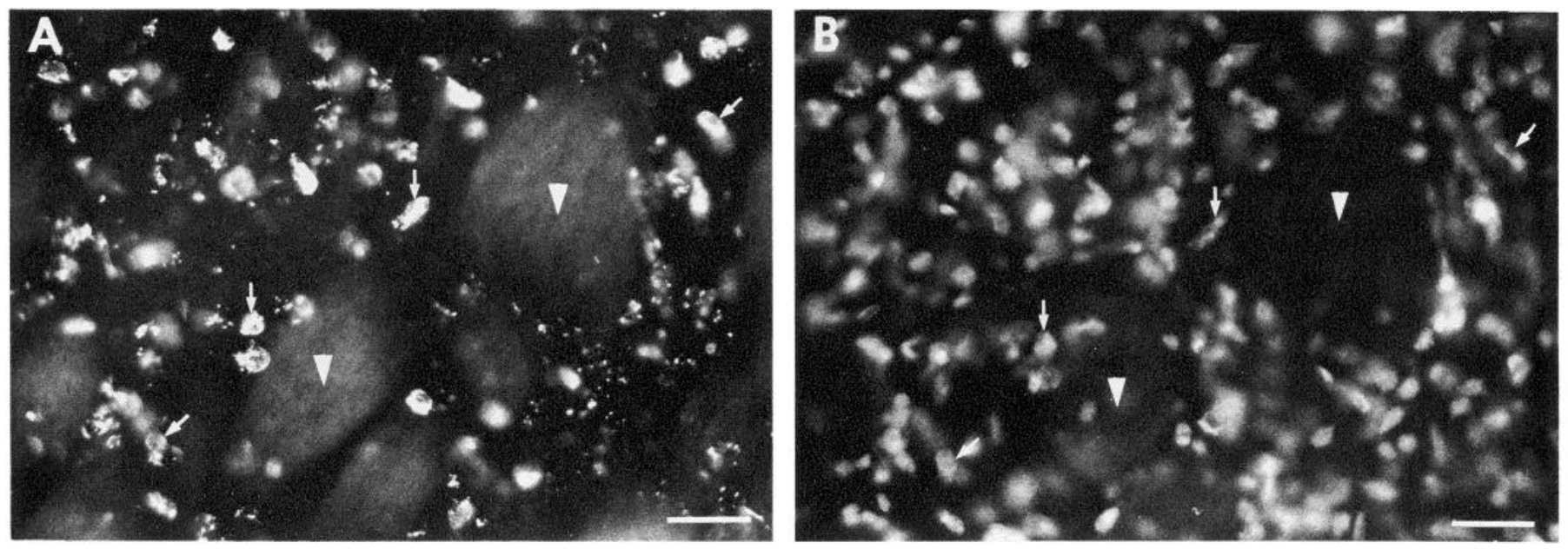

Figure 3. A, High-power fluorescent photomicrograph from a coronal section of the rat ventral caudate putamen showing a representative detail of the typical appearance and distribution of the NEP reaction product shown in Figure $2 B$. $B$, Ethidium bromide fluorescent counterstain of the same region of the caudate putamen as in Figure $3 A$ showing the corresponding distribution of cell bodies. Several examples of the codistribution of NEP reaction product $(A)$ and counterstained cell bodies $(B)$ are indicated (arrows). Axon bundles of the internal capsule are indicated by arrowheads. Scale bar, $30 \mu \mathrm{m}$ in $A, B$.

described (see Materials and Methods) and employed for NEP histochemistry. Curiously, we found that this soluble endopeptidase contaminant did not appear to generate a fluorescent reaction product in brain sections processed for NEP histochemistry with crude APM. Free-floating tissue sections stained with endopeptidase-contaminated APM showed a distribution of reaction product in all CNS regions which did not differ from that obtained with purified APM. This may be due to the dilution of the contaminating endopeptidase in the staining solution. Alternatively, if fluorescent reaction product were produced, it may not have adhered to the tissue after the washing to terminate the histochemical reaction. Hence, it also appears feasible to specifically localize NEP in the CNS using commercially available APM. Nevertheless, all the studies presented used endopeptidase-free APM.

We observed NEP to be localized at every level of the neuraxis. The enzyme was more richly and extensively localized in the forebrain, midbrain, and medulla. Within the diencephalon and pons, NEP showed a more restricted localization. Representative examples of the regional distribution of NEP at selected levels of the rat brain are seen in Figure 4, $A-G$. Throughout the neocortex, NEP displayed a laminar distribution. In the somatosensory cortex (Fig. 4A), for example, NEP staining was observed in cortical layers $2-6$, but was largely absent from layer 1. The localization of NEP in a sagittal section through the basal ganglia can be seen in Figure $4 B$, which shows extensive staining in the globus pallidus and intense NEP staining which localized to the central amygdaloid nucleus and, to a lesser degree, in the adjacent basolateral amydaloid nucleus and amygdalohippocampal area. In Figure $4 C$, a laminar staining pattern was also seen in the hippocampus, where a finely dispersed granular precipitate of NEP reaction product was densely localized over the granular cell layer of the dentate gyrus. Scattered staining was also seen over CA3 as well as in the diencephalon in several thalamic nuclei, including the paraventricular, lateral habenular, and mediodorsal thalamic nuclei (Fig. 4D). The cerebellum showed a similar staining pattern at all levels characterized by extensive staining over the granule cell layer (Fig. $4 E$ ). By contrast, only scattered staining was seen over the molecular layer.
The Purkinje cell layer appeared devoid of staining. The NEP localization within the pons was restricted to discrete nuclear groups, such as the dorsal tegmental nucleus and the mesencephalic nucleus of the trigeminal nerve (Fig. $4 F$ ). The medulla, like the forebrain, showed a particularly rich NEP localization. At all levels of the medulla, the spinal nucleus of the trigeminal nerve $(V)$ was richly stained whereas the region overlying the spinal tract of $\mathrm{V}$ was largely devoid of staining (Fig. $4 G$ ). The localization of NEP in the above regions, as well as in other regions discussed below, is summarized in Table 1 .

The partial distribution of NEP in the rat brain was examined in untreated and colchicine-treated animals. In general, the regional distribution of NEP was not altered by colchicine. Although NEP-positive cell bodies were commonly observed in untreated animals, it was often possible, in colchicinized animals, to observe enhanced NEP staining, particularly of the proximal processes of many populations of cells (Fig. 5). In the globus pallidus of a colchicine-treated animal, long extended processes of pallidal cell bodies were commonly visualized (Fig. $5 A$ ). By contrast, in an untreated animal, relatively few processes were usually seen (e.g., Fig. 9A). NEP reaction product localized to a dense plexus of fibers and cell bodies in the facial motor nucleus (Fig. 5B). The NEP-positive profiles of apparent magnocellular basal forebrain cells were commonly observed. Following colchicine treatment, long processes of these cells were visualized (Fig. $5 \mathrm{C}$ ). In the pons, the pedunculopontine tegmental nucleus displayed numerous fine, NEP-positive processes (Fig. 5D), in addition to some scattered cell bodies. This enhancement of NEP staining seen in response to colchicine suggests that the enzyme is synthesized in cell bodies and transported in cell processes.

Figures 6 and 7 show the relationship of NEP reaction product to cell bodies of varying size and morphology visualized by ethidium bromide fluorescent counterstain. Figure 6, $A$ and $B$, further indicates the laminar nature of the staining pattern in the hippocampus (see also Fig. $4 \mathrm{C}$ ). Dense reaction product localized over the pyramidal cell layer (Py) but was more sparsely distributed over the stratum oriens (Or) and the stratum radiatum (Rad). Despite the densely packed nature of the cells 

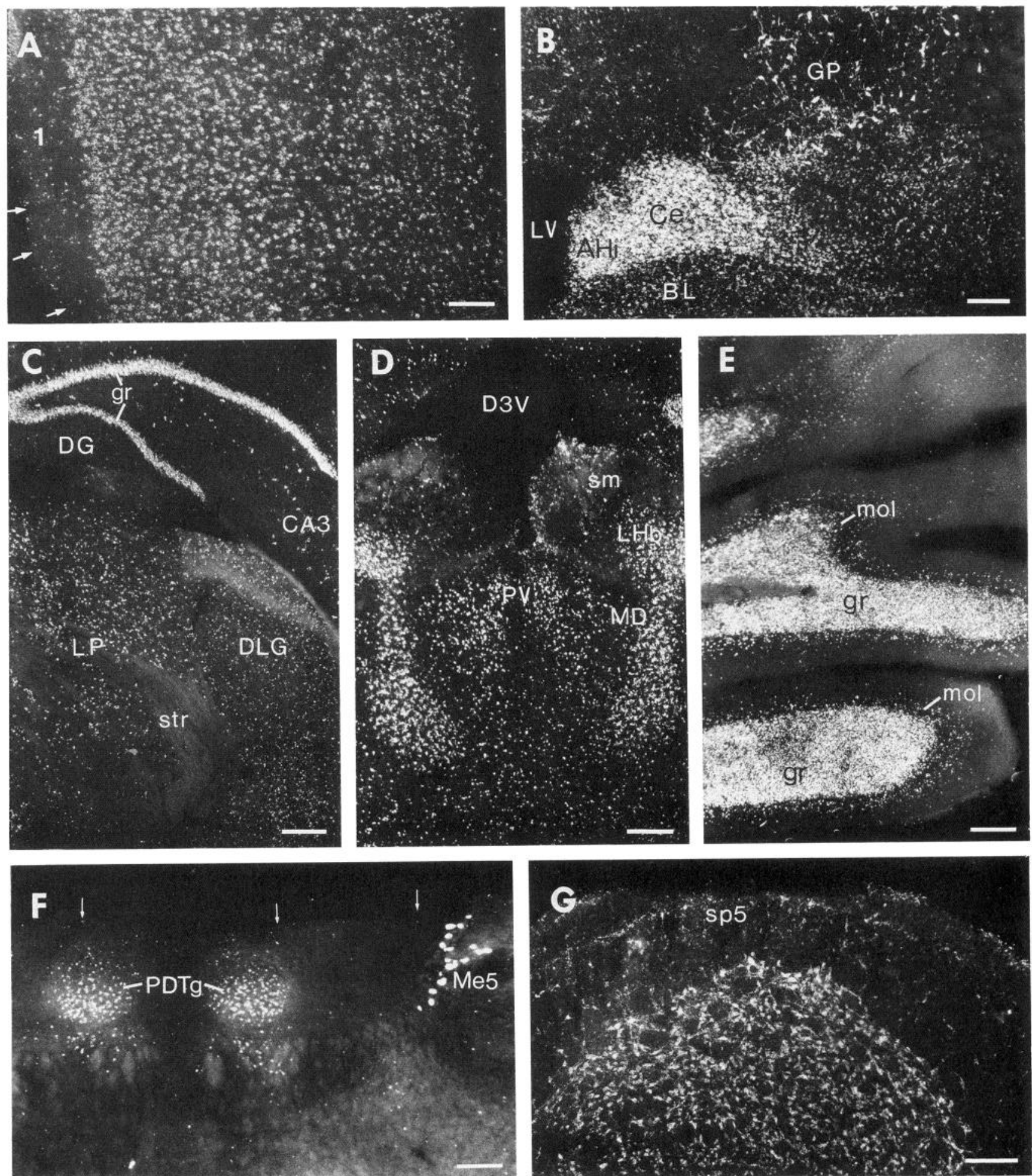

Figure 4. Low-power fluorescent photomicrographs of selected regions of the rat central nervous system showing characteristic features of the appearance and distribution of NEP reaction product. $A$, Temporal cortex at the level of the caudal diencephalon showing the enzyme distribution in cortical layers 1-6. Arrows indicate the pial surface. B, Parasagittal section of the forebrain showing the intense localization of NEP reaction product adjacent to the lateral ventricle $(L V)$ in the central amygdaloid nucleus $(\mathrm{Ce})$ as well as to the globus pallidus $(G P)$ and the basolateral amygdaloid nucleus (BL). $A H i=$ amygdalohippocampal/posteromedial cortical amygdaloid transition. Colchicine-treated ( $250 \mu \mathrm{g})$. $C$, Presence of an intense, finely dispersed reaction product over the granular cell layer $(g r)$ of the dentate gyrus $(D G)$ of the hippocampus with light staining over the $C A 3$. Scatteresd staining is seen over the lateral posterior thalamic nuclear group $(L P)$ and the dorsal lateral geniculate nucleus $(D L G)$. $D$, Rich NEP staining in the thalamus was observed at the level of the paraventricular thalamic nucleus $(P V)$. The richest staining was observed in the lateral habenular nuclei $(L H b)$ and the underlying mediodorsal thalamic nuclei $(M D)$. $s m=$ stria medullaris thalami; str $=$ superior thalamic radiation; $D 3 V=$ dorsal third ventricle. $E$, Representative staining in a coronal section showing 3 cerebellar folia at the level of the posterior dorsal tegmental nucleus of the pons (see $F$ ). Intense NEP staining is widely localized over the granule cell layer ( $g r$ ). Scattered staining is also present over the molecular cell layer $(\mathrm{mol}) . \mathrm{F}$, Two distinctly different staining patterns for NEP in this coronal section of the pons are seen in the posterior dorsal tegmental nucleus $(P D T g)$ and the mesencephalic nucleus of the trigeminal nerve $(M e 5)$. $G$. Coronal section of the caudal medulla showing the rich localization of NEP to the caudal spinal nucleus of the trigeminal nerve. $s p 5=$ spinal tract of the trigeminal nerve. The dorsal extent of the nucleus is at the left. Scale bar, $150 \mu \mathrm{m}$ in $A, 200 \mu \mathrm{m}$ in $B, G$, and $250 \mu \mathrm{m}$ in $C-F$. 
Table 1. List of abbreviations and distribution of cells (C), and fibers (F), and terminal-like fields (T) for neutral endopeptidase-24.11 and the enkephalins

\begin{tabular}{|c|c|c|c|}
\hline Abbreviation & Region & $\begin{array}{l}\text { Neutral } \\
\text { endopeptidase }\end{array}$ & Enkephalins $^{a}$ \\
\hline \multicolumn{4}{|l|}{ Telencephalon } \\
\hline $\mathrm{ACb}$ & Accumbens nucleus & $\mathrm{C}$ & $\mathrm{C} / \mathrm{F}$ \\
\hline ACo & Anterior cortical amygdaloid nucleus & $\mathrm{C}$ & $\mathbf{F}$ \\
\hline $\mathrm{AHi}$ & Amygdalohippocampal area & $\mathrm{C}$ & $\mathbf{F}$ \\
\hline BL & Basolateral amygdaloid nucleus & $\mathrm{C}$ & $\mathbf{F}$ \\
\hline CAl & Field CAl of Ammon's horn & $\mathrm{C}$ & $\mathrm{C}$ \\
\hline $\mathrm{CA} 3$ & Field CA3 of Ammon's horn & $\mathrm{C}$ & $\mathbf{F}$ \\
\hline $\mathrm{Ce}$ & Central amygdaloid nucleus & $\mathrm{C}$ & $\mathrm{C} / \mathrm{F}$ \\
\hline $\mathrm{CPu}$ & Caudate putamen (dorsal striatum) & $\mathrm{C}$ & $\mathrm{C} / \mathrm{F}$ \\
\hline DG & Dentate gyrus & $\mathbf{T}$ & $\mathrm{C}$ \\
\hline FrPaM & Frontoparietal cortex, motor area & $\mathrm{C}$ & $\mathbf{F}$ \\
\hline FrPaSS & Frontoparietal cortex, somatosensory area & $\mathrm{C}$ & $\mathbf{F}$ \\
\hline GP & Globus pallidus & $\mathrm{C}$ & $\mathbf{F}$ \\
\hline LS & Lateral septal nucleus & $\mathrm{C}$ & $\mathrm{C} / \mathrm{F}$ \\
\hline Py & Pyramidal cell layer, hippocampus & & \\
\hline Tu & Olfactory tubercle & $\mathrm{C}$ & $\mathrm{C} / \mathrm{F}$ \\
\hline \multicolumn{4}{|l|}{ Diencephalon } \\
\hline ARC & $\begin{array}{l}\text { Arcuate hypothalamic nucleus } \\
\text { Choroid plexus }\end{array}$ & $\mathbf{T}$ & $\mathrm{C} / \mathrm{F}$ \\
\hline DLG & Dorsal lateral geniculate nucleus & $\mathrm{C}$ & $\mathrm{F}$ \\
\hline EP & Entopeduncular nucleus & $\mathrm{C}$ & $\mathrm{C} / \mathrm{F}$ \\
\hline LHb & Lateral habenular nucleus & $\mathrm{C}$ & $\mathrm{F}$ \\
\hline LP & Lateral posterior thalamic nucleus (pulvinar) & $\mathrm{C}$ & $\mathbf{F}$ \\
\hline MD & Mediodorsal thalamic nucleus & $\mathrm{C}$ & $\mathbf{F}$ \\
\hline $\mathbf{M H b}$ & Medial habenular nucleus & $\mathrm{C}$ & $\mathbf{F}$ \\
\hline $\mathbf{M M}$ & Medial mammillary nucleus & $\mathrm{C}$ & $\mathrm{C} / \mathrm{F}$ \\
\hline PV & Paraventricular thalamic nucleus & $\mathrm{C}$ & $\mathbf{C} / \mathbf{F}$ \\
\hline VMH & Ventromedial hypothalamic nucleus & $\mathrm{C}$ & $\mathrm{C} / \mathrm{F}$ \\
\hline VPL & Ventroposterior thalamic nucleus & $\mathrm{C}$ & $\mathrm{F}$ \\
\hline \multicolumn{4}{|c|}{ Mesencephalon } \\
\hline CG & Central (periaqueductal) gray & $\mathrm{C}$ & $\mathrm{C} / \mathrm{F}$ \\
\hline Cnf & Cuneiform nucleus & $\mathrm{C}$ & $\mathrm{C} / \mathrm{F}$ \\
\hline IC & Inferior colliculus & $\mathrm{C}$ & $\mathrm{C} / \mathrm{F}$ \\
\hline IP & Interpeduncular nucleus & $\mathrm{C}$ & $\mathrm{C} / \mathrm{F}$ \\
\hline Me5 & $\begin{array}{l}\text { Nucleus of the mesencephalic tract of the } \\
\text { trigeminal nerve }\end{array}$ & $\mathrm{C}$ & $\mathbf{F}$ \\
\hline MG & Medial geniculate nucleus & $\mathrm{C}$ & $\mathrm{C} / \mathrm{F}$ \\
\hline SC & Superior colliculus & $\mathrm{C}$ & $\mathrm{C} / \mathrm{F}$ \\
\hline SNC & Substantia nigra, compact part & $\mathrm{C}$ & $\mathbf{F}$ \\
\hline SNR & Substantia nigra, reticular part & $\mathrm{C}$ & $\mathbf{F}$ \\
\hline \multicolumn{4}{|l|}{ Metencephalon } \\
\hline PPTg & $\begin{array}{l}\text { Pedunculopontine tegmental nucleus } \\
\text { Cerebellum, molecular layer } \\
\text { Cerebellum, granular layer }\end{array}$ & $\mathrm{C}$ & $\mathrm{C} / \mathrm{F}$ \\
\hline \multicolumn{4}{|c|}{ Myelencephalon } \\
\hline 7 & Facial nucleus & $\mathrm{C}$ & $\mathbf{F}$ \\
\hline 12 & Hypoglossal nucleus & $\mathrm{C}$ & $\mathbf{F}$ \\
\hline Gi & Gigantocellular reticular nucleus & $\mathrm{C}$ & $\mathrm{C} / \mathrm{F}$ \\
\hline IO & Inferior olivary nucleus & $\mathrm{C} / \mathrm{T}$ & $\mathbf{F}$ \\
\hline $\mathrm{ROb}$ & Raphe obscurus nucleus & $\mathrm{C} / \mathrm{F}$ & $\mathrm{C}$ \\
\hline SP5C & $\begin{array}{l}\text { Nucleus of the spinal tract of the trigeminal } \\
\text { nerve, caudal part }\end{array}$ & $\mathrm{C}$ & $\mathrm{C} / \mathrm{F}$ \\
\hline
\end{tabular}

a The distribution of enkephalinergic cell bodies and fibers is compiled from several immunocytochemical studies on the distribution of the enkephalins (Hökfelt et al., 1977; Simantov et al., 1977; Uhl et al., 1979; Wamsley et al., 1980; Finley et al., 1981; Sar et al., 1982; McGinty et al., 1985; Petrusz et al., 1985) and metenkephalin-arg-gly-leu (MERGL) (Petrusz et al., 1985; Fallon and Leslie, 1986) in the rat brain. 

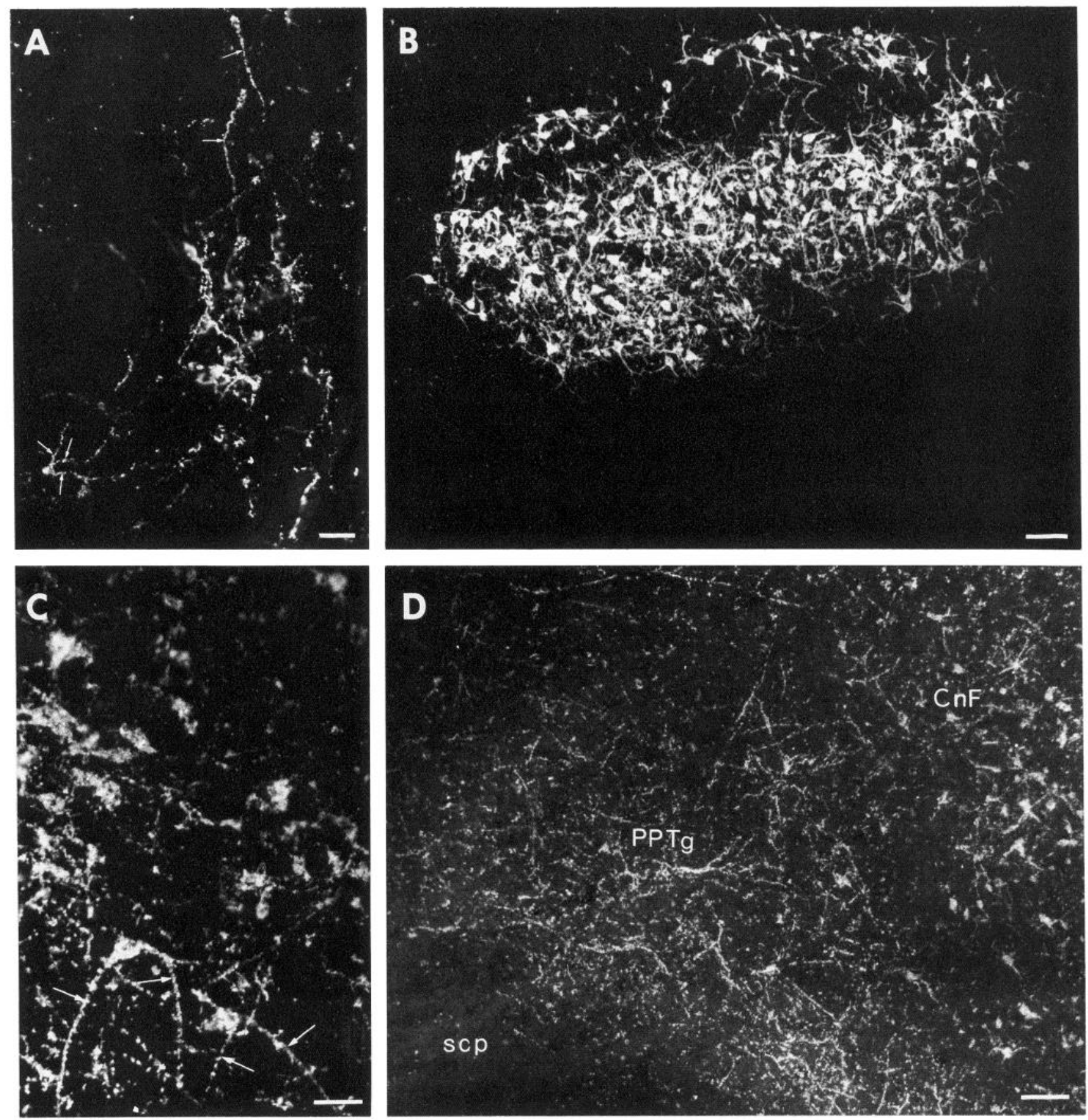

Figure 5. The enhanced visualization of NEP reaction product in cell processes in response to colchicine, as seen in 4 selected regions of a rat brain seen in parasagittal sections. $A$, Numerous extended processes (arrows) of cell bodies in the globus pallidus. See Figure $4 B$ for a representative low-power view of the relative distribution of the cell bodies seen here. $B$, A dense plexus of processes in the facial motor nucleus associated with numerous apparent motor neurons. $C$, Apparent magnocellular basal forebrain cells showing puncta of NEP reaction product delineating several cell processes (arrows). D, A dense plexus of NEP-positive fibers and scattered cell bodies are seen in the pedunculopontine tegmental nucleus $(P P T g)$. Numerous cell bodies and their associated processes are seen in the adjacent cuneiform nucleus $(\mathrm{CnF})$. $s c p$, superior cerebellar peduncle. Scale bar, $50 \mu \mathrm{m}$ in $A, C$, and $100 \mu \mathrm{m}$ in $B, D$.

in the pryamidal cell layer, it was possible to occasionally discern small "ringlets"' of reaction product which appeared to delineate the borders of these small cells (see arrows, Fig. $6 \mathrm{~A}$ ).

In Figure $6, C$ and $D, N E P$ is seen localized within part of the zona compacta of the substantia nigra. Most of the reaction product is distributed along the perimeter of these neurons (arrows), with relatively little staining observed over the cell nucleus. In addition, small discrete crystals of reaction product appear to delineate the proximal processes of a number of these cells (arrowheads). Figure $6, E$ and $F$, shows details of the cortical staining seen in Figure $4 A$. NEP was richly localized in cortical layers 2 and 3, but appeared to be largely absent from layer 1. Despite the high density of the reaction product, it appeared to follow the distribution of these small, densely packed cortical cells. In some instances, the reaction product appeared to colocalize with these cells, as suggested by the fact that "ring- 

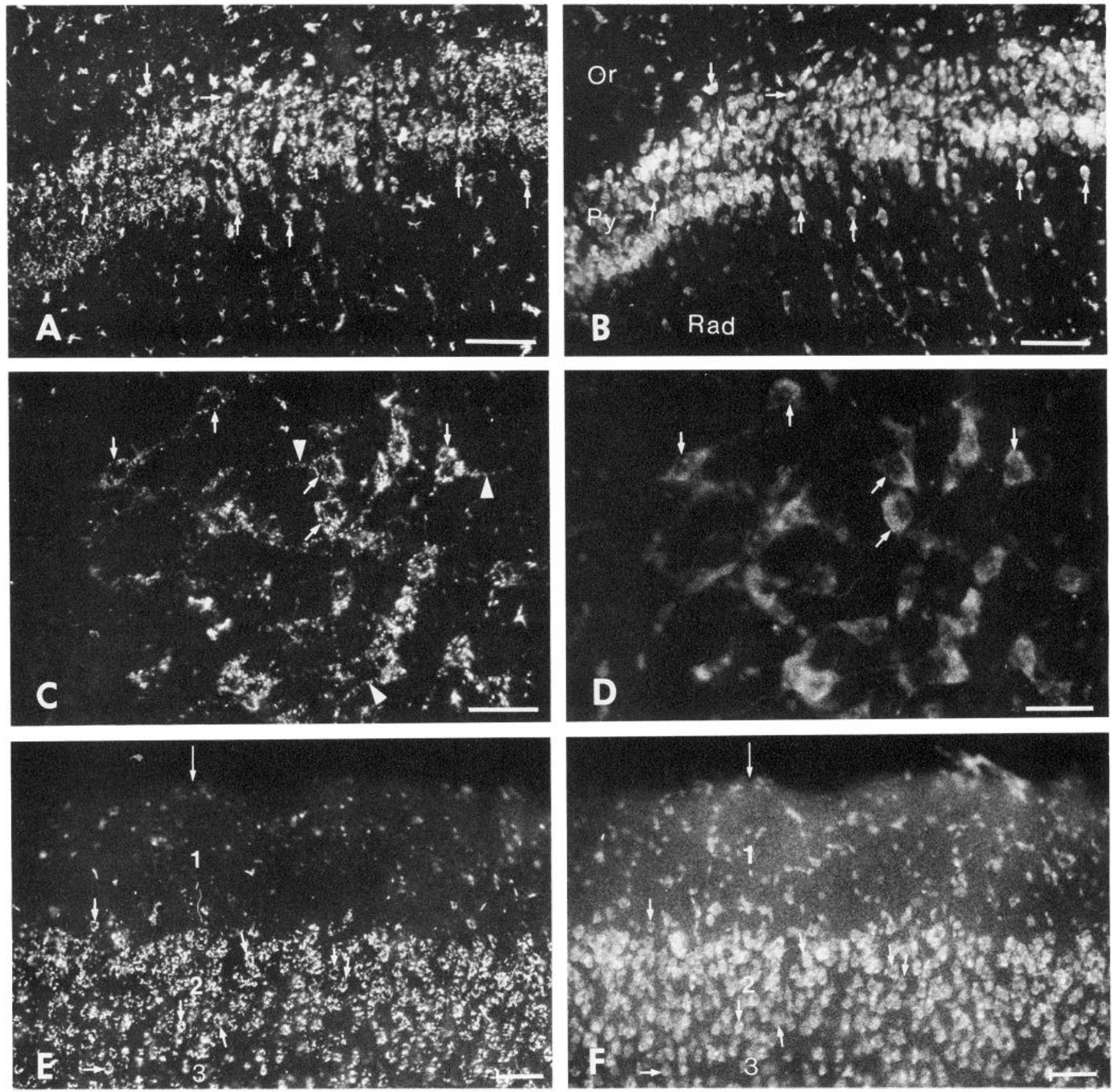

Figure 6. High-power fluorescent photomicrographs of coronal sections of selected regions of the rat brain showing the distribution of NEP reaction product $(A, C, E)$ relative to the corresponding distribution of ethidium bromide fluorescent counterstained cell bodies $(B, D, F)$. $A, B$, Dense staining overlies the pyramidal cell layer $(P y)$ of the hippocampus at the CAl transition. Lighter staining is seen in the adjacent stratum oriens $(O r)$ and the stratum radiatum $(R a d)$. Arrows indicate where the reaction product $(A)$ appears to codistribute with the counterstained cell bodies $(B)$. $C, D$, The distribution of reaction product in the substantia nigra, zona compacta $(C)$ appears to overlie the cytoplasm of the nigral cells (arrows) but is largely absent from the region corresponding to the cell nucleus. Several of the cells show a linear array of crystalline reaction product (arrowheads), which appears to be continuous with cell soma and which overlies the region of the cell corresponding to proximal cellular processes. $E, F$, Higher-power detail of staining in layers 1-3 of a region of the neocortex similar to that seen in Figure $4 A$. The long arrow indicates the pial surface. Whereas layer 1 is largely devoid of staining $(E)$, the staining in layers 2-3 closely parallels the distribution of the counterstained cell bodies $(F)$. There are several examples where the reaction product appears to form a small "ringlet" which appears to codistribute with the corresponding cell body (short arrows). Scale bar, $50 \mu \mathrm{m}$ in $A, B, 20 \mu \mathrm{m}$ in $C, D$ and $25 \mu \mathrm{m}$ in $E, F$.

lets" of reaction product could be seen overlying the cell bodies (small arrows, Fig. 6E).

NEP was also richly distributed in the medulla. In Figure $7 A$, staining was localized about the midline to 2 different regions, the inferior olivary nucleus and the raphe obscurus nucleus of the reticular formation. In the inferior olivary nucleus, NEP reaction product (Fig. $7 \mathrm{~B}$ ) appeared to codistribute with most of the cells of the nucleus (Fig. $7 C$ ) and delineated a central 

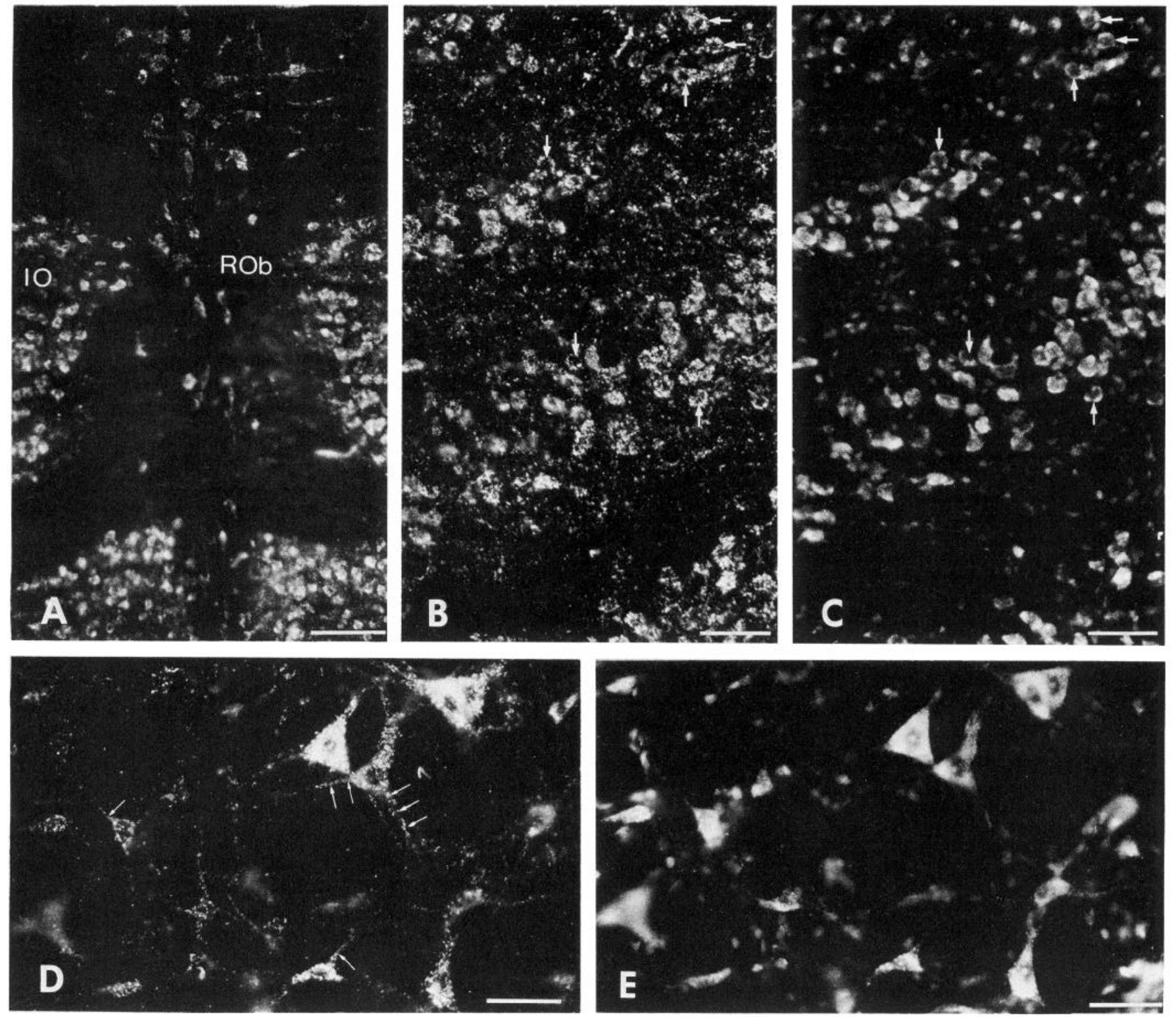

Figure 7. Low- $(A)$ and high-power $(B-E)$ photomicrographs of coronal sections of the rat ventral medulla. $A$, Bilaterally symmetrical NEP staining in the inferior olivary nucleus $(I O)$ and midline staining in the raphe obscurus nucleus $(R O b)$ of the medullary reticular formation. $B, C$, Higherpower detail of the NEP staining $(B)$ in the inferior olivary nucleus in a region lateral to that shown in $A$. The heaviest distribution of reaction product $(B)$ parallels the distribution of ethidium bromide counterstained cell bodies $(C)$. Several examples are shown where the reaction product appears to form small "rings" which overlie the region of the cells corresponding to the cell cytoplasm (arrows). There is considerably less staining over the nucleus of these cells. $D, E$, NEP staining $(D)$ in association with cell bodies of varying size and morphology $(E)$ in the gigantocellular reticular nucleus of the medulla. Note the 4 large cells at upper right which appear to contain densely packed crystals of reaction product in their cytoplasm and which sharply delineate the region corresponding to the nucleus of these cells. Arrows indicate a number of examples where reaction product appears to be associated with the proximal processes of reticular neurons. Scale bar, $50 \mu \mathrm{m}$ in $A, 20 \mu \mathrm{m}$ in $B, C$, and $25 \mu \mathrm{m}$ in $D, E$.

unstained region of the cells corresponding to the cell nucleus. Finely dispersed puncta of reaction product were also observed in the neuropil surrounding the olivary cells.

In Figure 7, $D$, and $E$, NEP reaction product was associated with cells of varying size and morphology in the gigantocellular reticular nucleus of the medulla. The cellular boundaries of 4 large neurons at the upper right in Figure $7 E$ were sharply delineated by reaction product (Fig. $7 D$ ). Dense staining over the cytoplasm of these neurons and the near absence of staining over the cell nucleus support a neuronal localization for NEP in this nucleus.
In order to examine the regional distribution of NEP and the enkephalins in the same tissue section, a study was conducted in the globus pallidus, a region rich in both NEP and the enkephalins. Figure 8 demonstrates the result of combined fluorescent histochemical localization of NEP with fluorescent immunocytochemical localization of the enkephalins. The NEP reaction product appeared to localize to numerous cell bodies in the globus pallidus (Fig. 8A, arrows). When the same section was viewed using a wide-band blue (fluorescein) excitation filter, the NEP cellular staining was found to closely overlap that of a dense plexus of enkephalinergic fibers in the globus pallidus 

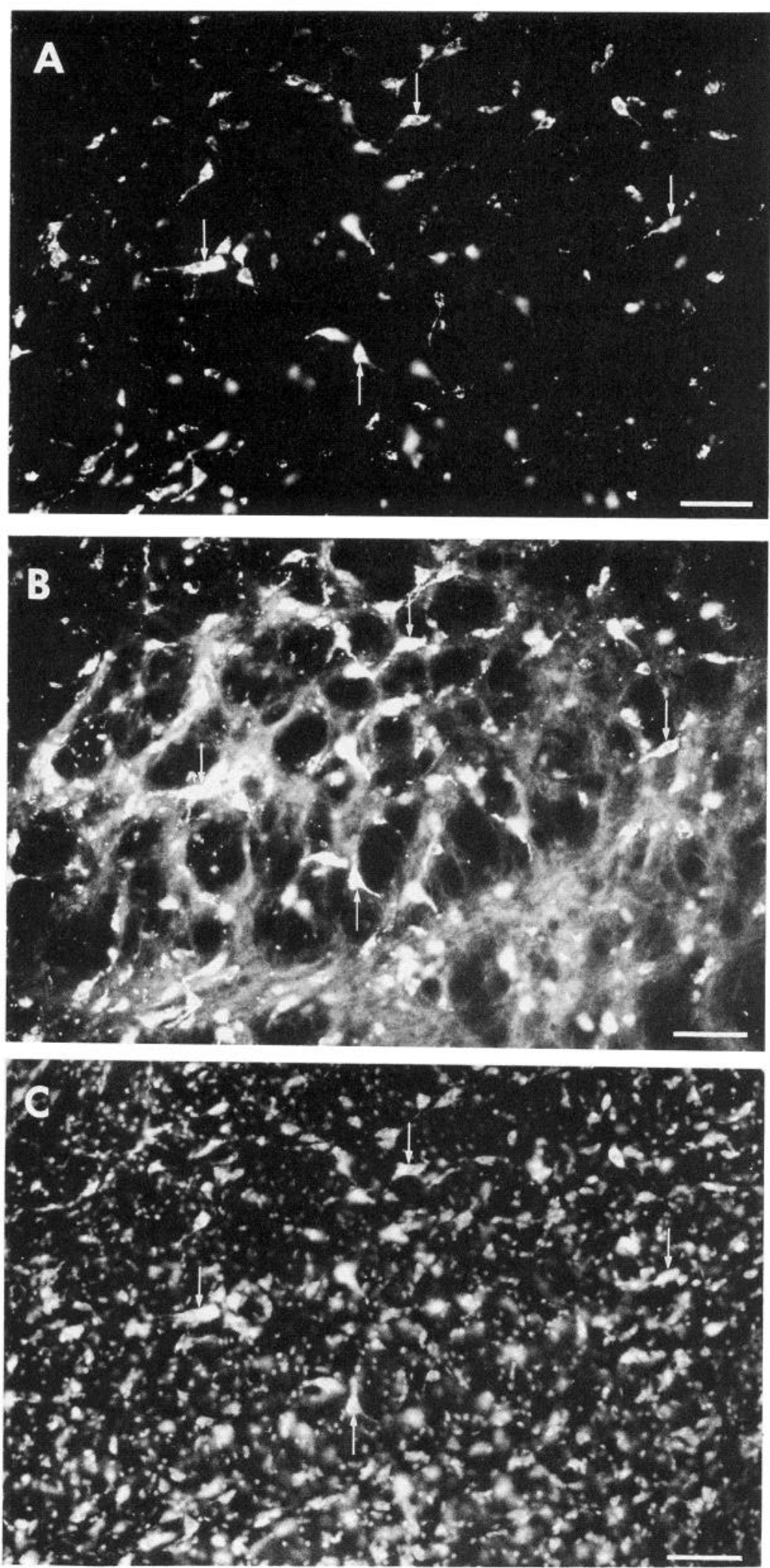

Figure 8. Fluorescent photomicrographs of a coronal section of the rat globus pallidus showing the extensive codistribution of NEP-positive cell bodies relative to rich plexuses of enkephalin-like immunoreactive fibers. $A$, Numerous NEP-positive cellular profiles including several with associated processes (arrows). B, The same section as in $A$ viewed with a wide-band blue (fluorescein) excitation filter permits visualization of the distribution of NEP reaction product relative to enkephalinlike immunoreactivity. Several of the NEP-positive cells indicated by arrows in $A$ are similarly indicated in $B$ and $C$. None of the NEP-positive cell profiles in $A$ were enkephalin immunoreactive. $C$, Corresponding distribution of neuronal and glial cellular elements as visualized by ethidium bromide fluorescent counterstain. Scale bar, $100 \mu \mathrm{m}$ in $A-C$.
(Fig. 8B). No enkephalin-like immunoreactive (EnkIR) cell bodies were observed. The corresponding distribution of cell bodies was visualized by ethidium bromide fluorescent counterstain (Fig. 8C). Based on these findings, we propose that NEP and the enkephalins in the globus pallidus are derived from different cell populations and that NEP is localized to an intrinsic population of pallidal neurons.

To test this hypothesis, injections of NMDA were made into the globus pallidus to examine the response of the NEP staining to this neurotoxic agent. Within $7 \mathrm{~d}$ after injection of NMDA, 
there was a marked alteration in the cellular distribution of NEP staining in the globus pallidus. The decrease in NEP staining became more pronounced when examined at longer survival periods $(3,8$, and 16 weeks). By 3 weeks after NMDA injection, minimal NEP staining persisted in the region of the injected globus pallidus (data not shown), which correlated with pronounced changes in the distribution of neural and glial elements. Pallidal neurons were rarely observed on the injected side, and those observed were shrunken, sharply angulated, and displayed a marked decrease in cytoplasm. Occasionally the cell nucleus was shifted to the perimeter of the cell. These signs of toxic injury were also accompanied by an infiltration of numerous darkly stained, small cells resembling microglia.

Figure 9 demonstrates the response of NEP to a direct injection of NMDA into the globus pallidus following a 16-week survival. Whereas the NEP staining in the uninjected globus pallidus (Fig. 9, $A, C$ ) delineated the profiles of large pallidal cell bodies (Fig. $9 E$ ), at longer survival periods ( 8 or 16 weeks) NEP staining was difficult to detect in much of the injected globus pallidus (Fig. 9, $B, D$ ). In contrast to shorter survival periods, at the survival periods of 8 or 16 weeks, no significant gliosis was observed in the NMDA-treated region (see Fig. $9 E$ vs $9 F$ ), and the scattered reaction product that persisted showed no apparent association with any cellular elements (Fig. 9F). The circumscribed nature of the lesion produced by NMDA was supported by the staining observed in adjacent areas, such as the reticular nucleus of the thalamus or the bed nuclei of the stria terminalis, which was indistinguishable on the injected and control sides. Moreover, no changes in NEP staining were observed in any other brain regions, including the caudate putamen or substantia nigra, at any of the survival periods examined.

In contrast to NEP histochemical staining, EnkIR appeared to be unaffected by NMDA at any level of the globus pallidus. A dense plexus of EnkIR processes was seen in the normal, untreated globus pallidus (Fig. 10A). Figure $10 B$ demonstrates the effect of NMDA injected 16 weeks previously into the contralateral globus pallidus. The distribution and intensity of the EnkIR in the injected globus pallidus did not appear to differ from the uninjected control side. There was, however, a marked diminution in EnkIR in the adjacent medial caudate putamen, into which the NMDA also diffused (see Fig. 10B).

\section{Discussion}

\section{Histochemical method}

The landmark study of Koelle and Friedenwald (1949) provided the impetus for studies visualizing neurotransmitter-metabolizing enzymes by histochemical techniques. With the rapid growth in the field of peptide pharmacology, it is becoming increasingly clear that the histochemical study of neuropeptidases will be important in understanding the mechanisms that regulate peptide biosynthesis and metabolism.
This report represents the first enzyme histochemical study to permit combined fluorescent visualization of a peptide neurotransmitter degrading enzyme together with its putative peptide substrate. The method employed to visualize NEP is adapted from the biochemical assay of NEP described by Orlowski and Wilk (1981) in which the substrate GaapMNA was ultimately degraded to free MNA. In order to visualize MNA, NSA was used as the capturing agent of MNA (Dolbeare and Smith, 1977; Smith, 1983). The marked sensitivity of rat brain NEP to azo dyes, such as fast blue $B$, precluded their use as capturing agents. It is noteworthy that in the present study NEP localization was accomplished at a pH of 7.4. Although Dolbeare and Smith (1977) noted that the rate of reaction of MNA and NSA at $37^{\circ} \mathrm{C}$ decreases as the $\mathrm{pH}$ of the reaction medium is raised from $\mathrm{pH} 4$ to 6 , there is apparently sufficient formation of a stable adduct of MNA and NSA at pH 7.4 to permit visualization of the NEP reaction product.

In order to visualize the reaction product, aminopeptidase cleavage of phe-MNA ( $I$ in Fig. 1) was required to release free MNA. In the absence of exogenous APM a low level of staining was observed, indicating that MNA could be slowly generated by aminopeptidases present in brain. The distribution of reaction product observed, however, did not differ from that obtained from sections incubated in the presence of excess exogenous APM. This is consistent with the observation that, in the CNS, APM activity is largely associated with cerebral blood vessels (Solhonne et al., 1987). To preclude the possibility that phe-MNA would diffuse from the site of its production, excess APM was added to the histochemical staining solution.

The specificity of the histochemical method for NEP was demonstrated using thiorphan, a specific inhibitor of NEP (Roques et al., 1980; Patey et al., 1981; Yaksh and Harty, 1982; Fournie-Zaluski et al., 1984); phosphoramidon, an NEP inhibitor first characterized in the kidney (Fulcher et al., 1982; Almenoff and Orlowski, 1984); JHF-26, a potent bidentate NEP inhibitor (B. Roques, personal communication); or captopril, a specific inhibitor of angiotensin-converting enzyme (Cushman et al., 1977). The fact that 3 structurally very different NEP inhibitors completely blocked all histochemical staining at a concentration near their $K_{\mathrm{i}}$ strongly supports the conclusion that the staining observed was derived from NEP activity and was not generated by other endogenous endopeptidase activities or by angiotensin-converting enzymes.

Given the broad emission spectrum of the NEP reaction product (Dolbeare and Smith, 1977; Smith, 1983), it was possible to visualize both NEP and the enkephalins by exciting both fluorophores simultaneously (e.g., Fig. 8B). Alternatively, to examine the codistribution of the enzyme and the peptide in the same cell bodies, the peptide immunoreactivity could be visualized using rhodamine-conjugated avidin, which has an emission spectrum that does not overlap with that of the NEP reaction product. This approach would afford greater sensitivity

\footnotetext{
Figure 9. Fluorescent photomicrographs showing NEP $(A-D)$ staining in a coronal section of the rat globus pallidus from an animal examined 16 weeks following injection of NMDA into the globus pallidus. $A, B$. Low-power photomicrographs demonstrating that, in contrast to the control side $(A)$, where numerous NEP-positive cellular profiles are seen, there is a striking loss of NEP staining in response to NMDA injection on the contralateral side $(B) . B S T L=$ lateral bed nucleus of the stria terminalis; $i c=$ internal capsule. $C-F$, Detail of a selected region from $A$ and $B$, corresponding to the letters $a$ and $b$ in each figure, which are indicated for orientation. These high-power fluorescent photomicrographs show the distribution of NEP reaction product on the control $(C)$ and treated $(D)$ sides relative to the corresponding distribution of ethidium bromide fluorescent counterstained cell bodies $(E, F)$. On the control side $(C)$, NEP reaction product colocalizes with numerous large pallidal cell bodies $(E)$, some of which are indicated (arrows). Note the absence of gliosis in the NMDA-treated tissue $(F)$, which reflects the prolonged survival time of the animal. Scale bar, $100 \mu \mathrm{m}$ in $A, B$ and $50 \mu \mathrm{m}$ in $C-F$.
} 

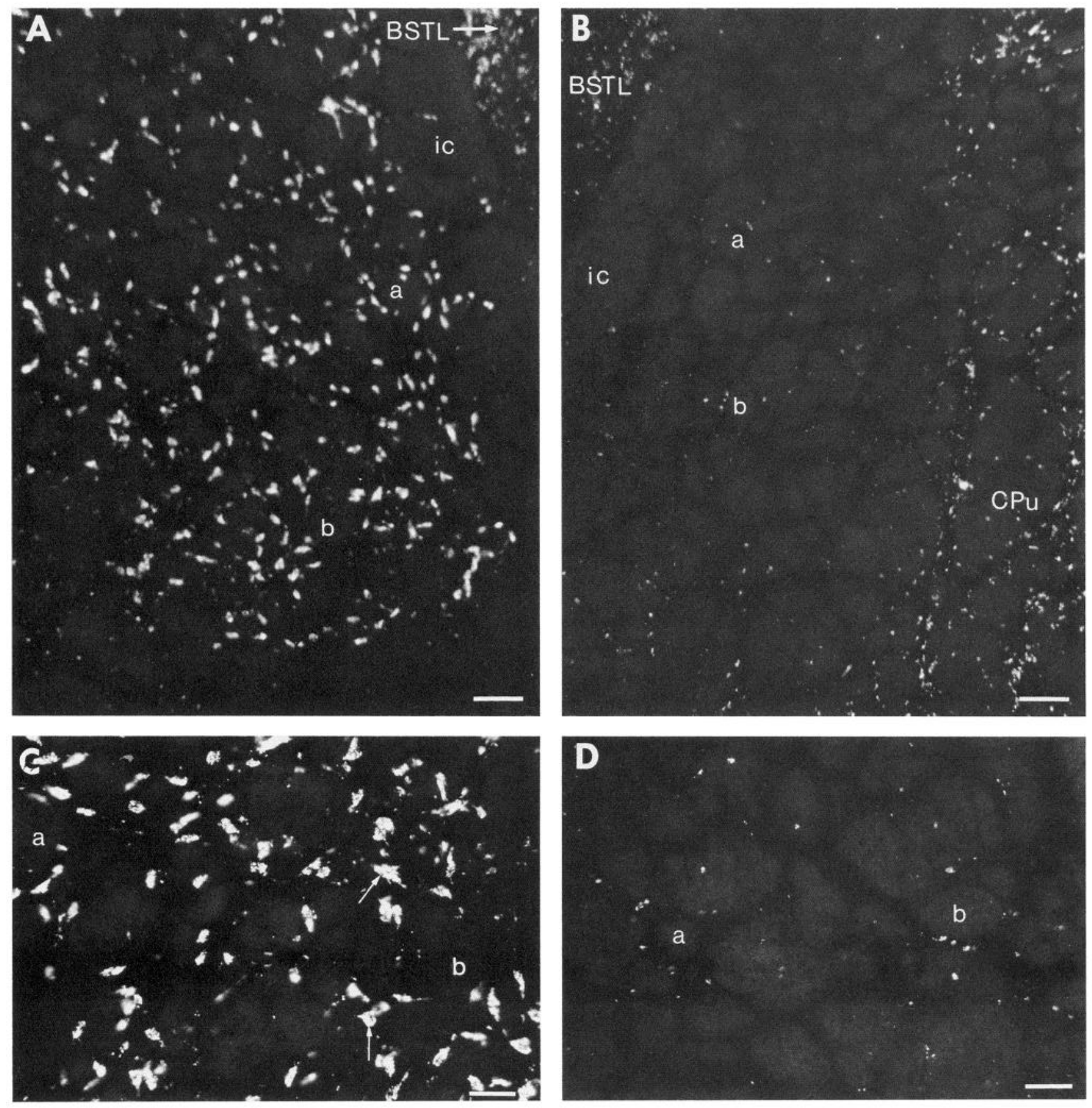

D
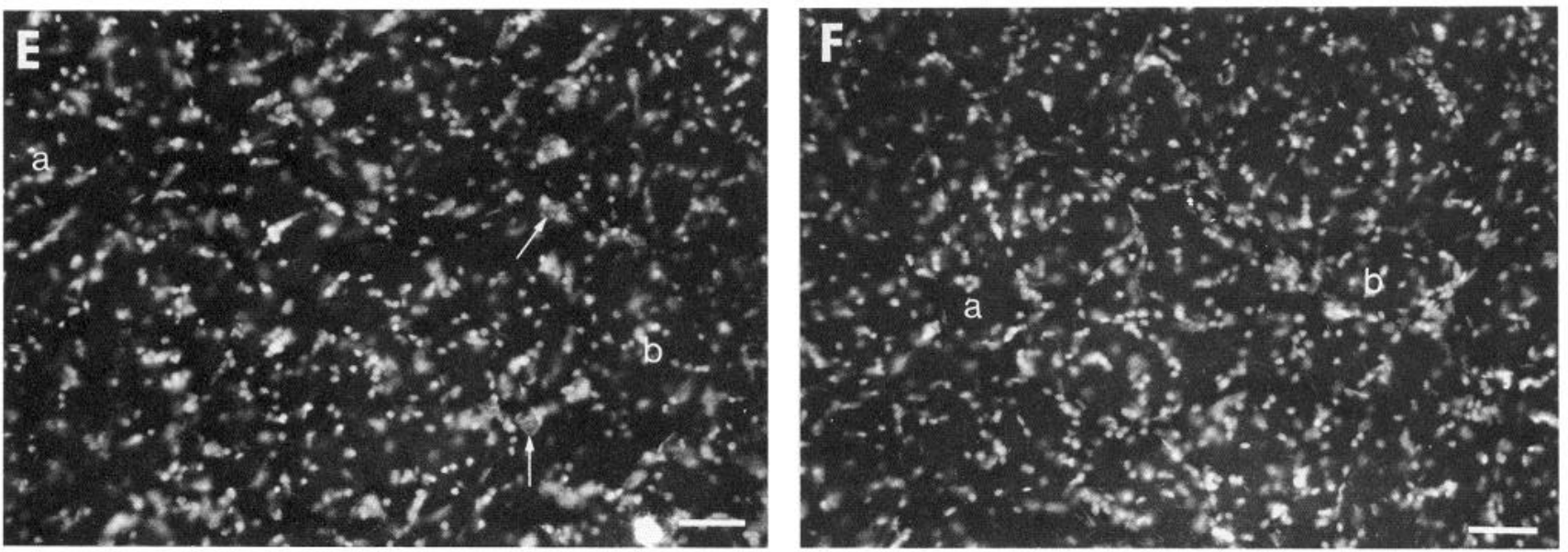

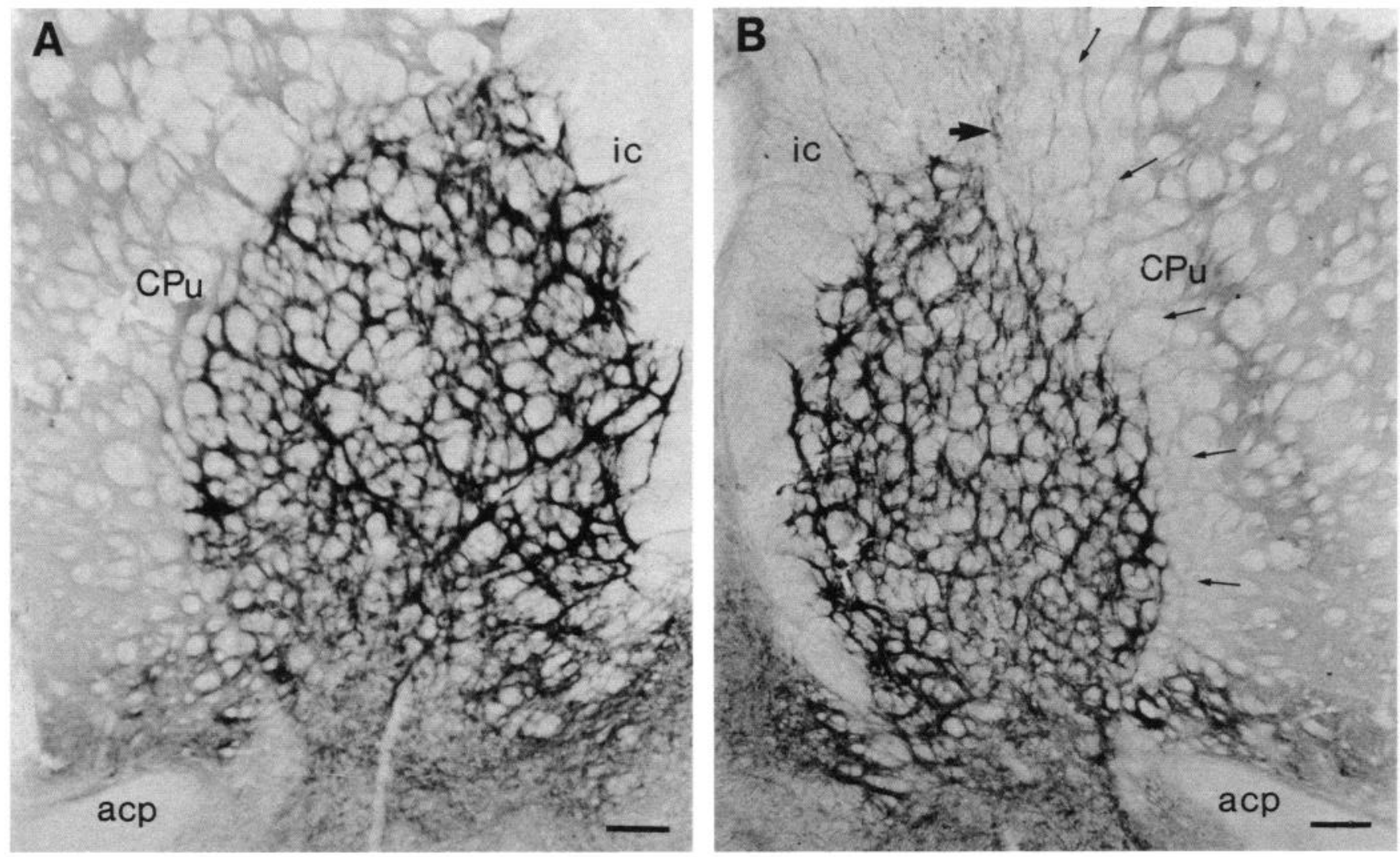

Figure 10. A, B, Low-power bright-field photomicrographs showing the appearance and distribution of EnkIR in a coronal section of the rat globus pallidus adjacent to that from the NEP-stained section shown in Figure 9. The globus pallidus on the control side (Figs. $9 A, 10 A$ ) is somewhat more rostral to that on the NMDA-treated side (Figs. $9 B, 10 B$ ). There was no significant difference in the intensity, appearance, or distribution of EnkIR on the control $(A)$ versus NMDA-treated $(B)$ sides of the globus pallidus. EnkIR was decreased, however, in the adjacent caudate putamen $(C P u)$ in response to the apparent diffusion of the NMDA into this region (arrows in $B$ ). By contrast, on the control side $(A)$ the EnkIR in the $C P u$ did not diminish in intensity at the medial border of the $C P u$. $a c p=$ anterior commissure, posterior. Scale bar, $200 \mu \mathrm{m}$ in $A, B$.

where a bright emission from the NEP fluorescent reaction product might mask a weaker fluorescent signal for the peptide.

\section{Regional and cellular localization of NEP}

The validity of our NEP histochemical method is supported by the close agreement among this and previous reports of the regional localization of NEP. It is noteworthy that we localized NEP to the same regions previously reported autoradiographically (Waksman et al., 1986; Pollard et al., 1987a, b). In addition, we localized NEP to several additional regions, including several cranial nerve nuclei, the inferior olivary nuclei, and nuclei of the reticular formation. This more extensive localization may reflect the increased sensitivity of the histochemical method, as well as the use of colchicine.

A principal advantage of the present histochemical method is the ability to localize NEP activity to cell bodies and processes. Often, cell bodies were observed to have the highest density of reaction product along the perimeter of the cells. This may reflect the presence of NEP in the plasma membrane (De la Baume et al., 1981; Devault et al., 1988). In close agreement with the present study, a recent in situ hybridization study has also found NEP mRNA to be localized to numerous cell bodies of the rat caudate putamen (Burke et al., 1988; A. Mansour, personal communication). In other regions, the distribution of reaction product may be derived from NEP-positive terminal fields contacting the cell bodies. The enhanced visualization of proximal cell processes following colchicine treatment also supports an intracellular site of synthesis and transport of NEP in some cell populations. The difference in metabolic stability of peptides relative to larger proteins may account for the fact that peptides, unlike some enzymes, are not readily visualized in cell processes and terminals after colchicine treatment.

Evidence for the localization of NEP to some neuronal cell groups was supported by the size and morphology of the cells and associated processes that stained for NEP. Many mediumand large-sized cell bodies ranging in size from 15 to 30 microns were observed to stain for NEP. These included cell bodies in the globus pallidus, the substantia nigra, the reticular formation of the medulla, and several cranial nerve nuclei. These cells displayed varying morphology (e.g., fusiform or multipolar) characteristic of the neuronal populations present in these regions. A neuronal localization for NEP is also supported by our finding that there is a rapid decrease in NEP staining in the hypoglossal nucleus following hypoglossal nerve axotomy, which is consistent with the biosynthesis of NEP by hypoglossal motoneurons (Back et al., 1989). Although we cannot exclude the possibility that NEP may also be localized to glia, we did not observe reaction product to codistribute with glial cells visualized by ethidium bromide counterstain. In regions predominantly consisting of white matter, such as the funiculi of the spinal cord (Back and Gorenstein, 1989) or the internal capsule, NEP reaction product was notably absent despite prolonged histochemical staining. A recent ultrastructural study localized 
NEP immunoreactivity to axonal profiles in the globus pallidus, but also did not detect any labeled glial elements (Barnes et al., 1988).

In a number of brain regions, the appearance and distribution of reaction product did not appear to be cellular in nature. Rather, the reaction product had a finely dispersed appearance suggestive of a localization in small terminal processes. This was observed in the dentate gyrus of the hippocampus (Fig. 4C) and the inferior olivary nucleus (Fig. 7B). Ultrastructural localization of the enzyme in these areas will be required to ascertain the precise nature of the enzyme's localization.

Further evidence for a neuronal localization of NEP is provided by several other studies. Matsas et al. (1986) have reported the immunocytochemical visualization of NEP in neuropil which stained positively for neurofilament protein but not for glial fibrillary acidic protein. Kainic acid induced a marked decrease in NEP levcls in the caudate putamen, also supporting a localization to striatal neurons (Pollard et al., 1987a; Waksman et al., 1987).

\section{NEP and the enkephalins}

This report and other light microscopic mapping studies of the distribution of NEP in the nervous system of the rat (Back and Gorenstein, 1985, 1989; Waksman et al., 1986, 1987; Pollard et al., 1987a, b) and the pig (Matsas et al., 1986) are in good agreement regarding an extensive correlation among the regional distributions of NEP, mu and delta opiate receptors, and the enkephalins. In a combined autoradiographic study, Waksman et al. (1986) found that the distribution and relative levels of NEP and the mu and delta opiate receptors correlated closely. In a separate study, NEP and mu and delta receptor levels in the caudate putamen were observed to decrease at different rates following a striatal kainate injection (Waksman et al., 1987).

We found the regional distribution of NEP to overlap closely that of enkephalin-containing brain regions. We have also found a good correlation between NEP- and enkephalin-containing regions at all levels of the spinal cord (Back and Gorenstein, 1989). In all regions where NEP was localized, EnkIR has also been reported (see Table 1). In some regions (e.g., accumbens n., central amygdaloid n., globus pallidus, substantia nigra, and spinal trigeminal $n$.), the rich level of the peptide correlates with an extensive NEP distribution. In other areas (e.g., the caudate putamen, inferior colliculus, cerebellum, and choroid plexus), the distribution of NEP appears to be more extensive than that of the enkephalins or other peptides, such as substance P. In areas where NEP is more extensively localized than the enkephalins, the mismatch may reflect a level of peptide too low to detect in postmortem tissue. Alternatively, the level of NEP in terminal fields associated with sites of enkephalin release may be too low to detect. NEP may also degrade one or more peptides (e.g., SP, CCK-8, or neurotensin), in addition to the enkephalins. The extensive distribution of NEP in some regions may reflect the global release of peptide acting in a neuroendocrine fashion. NEP may also be expressed in cells which, during development, displayed transient enkephalinergic expression that is undetectablc in the adult animal.

Given that no single relationship of enkephalinergic and NEPpositive cellular elements was suggested from an examination of the gross regional distributions of the enzyme and peptide (see Table 1), we developed a method to covisualize NEP and the enkephalins in the same tissue section. We chose to examine the globus pallidus, a brain region where mismatch between the enkephalins and opiate receptors exists. In contrast to the opiate receptors, NEP activity was richly localized to the globus pallidus in regions rich in enkephalinergic fiber pathways. NEP. positive cellular profiles appeared to coincide with essentially all pallidal neurons observed by ethidium bromide fluorescent counterstain. Since enkephalinergic perikarya are apparently absent in the globus pallidus (Brann and Emson, 1980; Correa et al., 1981; Palkovits et al., 1981; Del Fiacco et al., 1982), we conclude that the majority of the NEP in the globus pallidus derives from a population of cells separate from that contributing to the enkephalins. This conclusion is supported by the pronounced loss of NEP reaction product in the globus pallidus following NMDA treatment (Fig. 9, $B, D$ ) and the lack of apparent change in EnkIR elements (Fig. 10B). The neurotoxic action of NMDA, like that of kainate and ibotenate, occurs through a tonic activation of glutamate receptors present on neuronal cell bodies while sparing fibers of passage (Stewart et al., 1986). The high concentration of NMDA receptors present in the globus pallidus (Monaghan and Cotman, 1985) accounts for the potent depletion of NEP activity in the pallidum by NMDA and suggests that both NEP and the NMDA receptor may colocalize to neurons of the globus pallidus. This possible link between the opiate system and the actions of excitatory amino acids is consistent with recent studies noting opioid peptide modulation of the effects of NMDA in the hypothalamus (Cicero et al., 1988) and the spinal cord (Caudle and Isaac, 1988).

It is noteworthy that NMDA (Stewart et al., 1986), unlike kainate (Guldin and Markowitsch, 1982; Köhler and Schwarcz, 1983), has not been reported to cause damage to secondary cell populations distal to the site of injection. We found the NMDAinduced loss of NEP staining to be restricted to the globus pallidus. There was no observable change in NEP staining in the caudate putamen, the reticular nucleus of the thalamus, or the substantia nigra, all NEP-rich regions that receive known pallidal projections. Kainate injection into the caudate putamen has been reported to cause a $21 \%$ decrease in NEP levels in the globus pallidus, as determined by autoradiography (Waksman et al., 1987). This response was interpreted to indicate a striatopallidal NEP-containing pathway. Alternatively, given that kainate, unlike NMDA, can cause damage distal to the site of injection, the decrease in NEP in response to kainate may reflect a postsynaptic decrease in the synthesis of NEP by pallidal neurons.

The pronounced depletion of EnkIR elements in the ventromedial caudate putamen in response to NMDA, in contrast to the lack of apparent change in the globus pallidus (Fig. 10B), is consistent with localization of the enkephalins to numerous neuronal cell bodies in the ventral and caudolateral regions of the caudate putamen (Pickel et al., 1980). We have also observed a pronounced loss of NEP staining in cell bodies in the caudate putamen in response to NMDA (Back et al., 1988).

\section{Functional considerations}

The present results support the localization of NEP to the soma and processes of neurons of the globus pallidus where the enzyme may be situated to degrade enkephalins released onto these neurons from the extensive surrounding fiber pathways. Ultrastructural studies have demonstrated multiple enkephalinergic symmetrical synapses with the dendrites and perikarya of pallidal neurons (Somogyi et al., 1982). Given that essentially all pallidal neurons stain for NEP, it is likely that many of these NEP-positive neurons receive direct enkephalinergic synaptic 
contacts. A relatively sparse number of unmyelinated axons, of unknown origin, in the pig globus pallidus have also been shown ultrastructurally to contain NEP immunoreactivity (Barnes et al., 1988). Perhaps these unmyelinated axons are the local collaterals of pallidal projection neurons (Falls et al., 1983). In the rat, myelinated enkephalin and substance $P$ striatal axonal efferents from medium-sized spiny cells may terminate in the globus pallidus (Pickel et al., 1980; Somogyi et al., 1982; Bolam et al., 1983).

We have previously reported NEP and the enkephalins to display the same topographic relationship in the hypoglossal nucleus of the medulla as found here in the globus pallidus (Back et al., 1989). In both the forebrain and the brain stem, NEP is synthesized in essentially all the cells of a nucleus in close juxtaposition to enkephalinergic fibers or varicosities which have been shown to make synaptic contacts on these cells. Hence, in these regions, enkephalins may be released with subsequent metabolism of the peptide by NEP made in the postsynaptic cell.

This does not exclude the possibility that NEP in some regions may be presynaptically synthesized with the enkephalins and transported to the same terminal fields. In the substantia gelatinosa of the spinal cord, NEP localizes extensively to an intrinsic population of interneurons (S. A. Back, J. E. Swett, and C. Gorenstein, unpublished observations; B. Roques, personal communication). This region is also rich in enkephalinergic interneurons. Hence, it is possible that enkephalinergic interneuron populations associated with local peptide release may contain the enzyme and the peptide. By contrast, enkephalinergic projection ncurons may impinge on target neurons (e.g., those of the globus pallidus and hypoglossal nucleus), which separately express NEP in the soma and processes of these cells. Hence, NEP may be analogous to acetylcholinesterase, which can be synthesized by both pre- and postsynaptic elements of the motor end-plate.

The histochemical method developed in the present study need not be limited to the study of NEP. A growing number of endopeptidases and other proteolytic activities have been recently identified in the CNS, the peripheral nervous system, and the adrenal gland (Turner et al., 1985; Supattapone et al., 1988). Methods for the anatomical localization of proteases in nervous tissue have been limited by the lack of suitable antibodies or radiolabeled ligands of sufficient sensitivity to permit the identification of low enzyme levels in the tissue. These difficulties may be overcome using a histochemical approach. Based on the known specificities of a given protease, synthctic pcptide substrates can be designed that will release naphthylamine for subsequent coupling with NSA. Our demonstration that this approach is feasible at neutral $\mathrm{pH}$ suggests that other membranebound proteases with roles in peptide processing and metabolism may be visualized using a histochemical approach.

\section{References}

Almenoff, J., and M. Orlowski (1984) Biochemical and immunological properties of a membrane-bound brain metalloendopeptidase: Comparison with thermolysin-like kidney neutral metalloendopeptidase. J. Neurochem. 42: 151-157.

Almenoff, J., S. Wilk, and M. Orlowski (1981) Membrane bound pituitary metalloendopeptidase: Apparent identity to enkephalinase. Biochem. Biophys. Res. Commun. 102: 206-214.

Back, S. A., and C. Gorenstein (1985) Localization of neutral metalloendopeptidase (enkephalinase) activity in rat brain by fluorescent histochemistry. Soc. Neurosci. Abstr. 11: 389.
Back, S. A., and C. Gorenstein (1989) Fluorescent histochemical localization of neutral endopeptidase-24.11 (enkephalinase) in rat spinal cord. J. Comp. Neurol. 280: 436-450.

Back, S. A., M. E. Hargreaves, J. E. Swett, and C. Gorenstein (1988) Localized lesion of neurons with N-methyl-D-aspartate (NMDA): Support for a neuronal localization of endopeptidase-24.11 (enkephalinase) in forebrain. Soc. Neurosci. Abstr. 14: 545.

Back, S. A., M. E. Hargreaves, and C. Gorenstein (1989) Coordinate decrease in enkephalinase and cholinergic enzyme staining in response to hypoglossal axotomy supports a role for enkephalinase in neurotransmission. Adv. Biosci. 75: 321-324.

Barnes, K., A. J. Turner, and A. J. Kenny (1988) Electronmicroscopic immunocytochemistry of pig brain shows that endopeptidase-24.11 is localized in neuronal membranes. Neurosci. Lett. 94: 64-69.

Bolam, J. P., P. Somogyi, H. Takagi, I. Fodor, and A. D. Smith (1983) Localization of substance P-like immunoreactivity in neurons and nerve terminals in the neostriatum of the rat: A correlated light and electron microscopic study. J. Neurocytol. 12: 325-344.

Brann, M. R., and P. C. Emson 1980) Microiontophoretic injection of fluorescent tracer with simultaneous immunofluorescent histochemistry for the demonstration of efferents from the caudate-putamen projecting to the globus pallidus. Neurosci. Lett. 16: 61-65.

Burke, S., L. Hersh, S. Unnithan, R. Chipkin, M. K. Schafer, A. Mansour, and S. J. Watson (1988) Localization and regulation of rat kidney enkephalinase: An in situ hybridization analysis. Soc. Neurosci. Abstr. 14: 545 .

Caudle, R. M., and L. Isaac (1988) A novel interaction between dynorphin(1-13) and an $N$-methyl-D-aspartate site. Brain Res. 443: 329332.

Chipkin, R. E., J. G. Berger, W. Billard, L. C. Iorio, R. Chapman, and A. Barnett (1988) Pharmacology of SCH 34826, an orally active enkephalinase inhibitor analgesic. J. Pharmacol. Exp. Ther. 245: 829838.

Cicero, T. J., E. R. Myer, and R. D. Bell (1988) Characterization and possible opioid modulation of $N$-methyl-D-aspartic acid induced increases in serum luteinizing hormone levels in the developing male rat. Life Sci. 42: 1725-1732.

Coons, A. H. (1958) Fluorescent antibody mcthods. In General $\mathrm{Cy}$ tochemical Methods, J. D. Danielli, ed., pp. 399-422, Academic, New York.

Correa, F. M. A., R. B. Innis, L. D. Hester, and S. H. Snyder (1981) Diffuse enkephalin innervation from caudate to globus pallidus. Neurosci. Lett. 25: 63-68.

Craves, F. B., P. Y. Law, and H. H. Loh (1978) The metabolic disposition of radiolabelled enkephalins in vitro and in situ. J. Pharmacol. Exp. Ther. 206: 492-506.

Cushman, D. W., H. S. Cheung, E. F. Sabo, and M. A. Ondetti (1977) Design of potent competitive inhibitors of angiotensin-converting enzyme. Carboxyalkanoyl and mercaptoalkanoyl amino acids. Biochemistry 16: 5484-5490.

De la Baume, S., G. Patey, and J.-C. Schwartz (1981) Subcellular distribution of enkephalin-dipeptidyl carboxypeptidase (enkephalinase) in rat brain. Neuroscience 6: 315-321.

Del Fiacco, M., G. Paxinos, and A. C. Cuello (1982) Neostriatal enkephalin-immunoreactive neurons project to the globus pallidus. Brain Res. 231: 1-17.

Devault, A., C. Nault, M. Zollinger, M.-C. Fournie-Zaluski, B. P. Roques, P. Crine, and G. Boileau (1988) Expression of neutral endopeptidase (enkephalinase) in heterologous COS-1 cells. J. Biol. Chem. 263: 40334040 .

Dolbeare, F. A., and R. E. Smith (1977) Flow cytometric measurement of peptidases with use of 5-nitrosalicylaldehyde and 4-methoxy- $\beta$ naphthylamine derivatives. Clin. Chem. 23: 1485-1491.

Fallon, J. H., and F. M. Leslie (1986) Distribution of dynorphin and enkephalin peptides in the rat brain. J. Comp. Neurol. 249: 293-336.

Falls, W. H., M. R. Park, and S. T. Kitai (1983) An intracellular HRP study in the rat globus pallidus. II. Fine structural characteristics and synaptic connections of medially located large GP neurons. J. Comp. Neurol. 220: 229-245.

Finley, J. C. W., J. L. Maderdrut, and P. Petrusz (1981) The immunohistochemical localization of enkephalin in the central nervous system of the rat. J. Comp. Neurol. 198: 541-565.

Fournie-Zaluski, M. C., P. Chaillet, E. Soroca-Lucas, H. Marçais-Collado, J. Constentin, and B. P. Roques (1983) New carboxyalkyl inhibitors of brain enkephalinase: Synthesis, biological activity, and analgesic properties. J. Med. Chem. 26: 60-65. 
Fournie-Zaluski, M. C., E. Lucas, G. Waksman, and B. P. Roques (1984) Differences in the structural requirements for selective interaction with neutral metalloendopeptidase (enkephalinase) or angiotensin-converting enzyme. Molecular investigation by use of new thiol inhibitors. Eur. J. Biochem. 139: 267-274.

Fulcher, I. S., R. Metsas, A. J. Turner, and A. J. Kenny (1982) Kidney neutral endopeptidase and the hydrolysis of enkephalin by synaptic membranes show similar sensitivity to inhibitors. Biochem. J. 203: 519-522.

Gorenstein, C., and S. H. Snyder (1979) Two distinct enkephalinases: Solubilization, partial purification, and separation from angiotensin converting enzyme. Life Sci. 25: 2065-2070.

Gorenstein, C., and S. H. Snyder (1980) Enkephalinases. Proc. R. Soc. London Ser. B. 210: 123-132.

Guldin, W. O., and H. J. Markowitsch (1982) Epidural kainate, but not ibotenate, produces lesions in local and distant regions of the brain. A comparison of the intracerebral actions of kainic acid and ibotenic acid. J. Neurosci. Meth. 5: 83-93.

Hersh, L. B. (1982) Degradation of enkephalins: The search for an enkephalinase. Mol. Cell. Biochem. 47: 35-43.

Hersh, L. B. (1984) Reaction of opioid peptides with neutral endopeptidase ("enkephalinse"). J. Neurochem. 43(2): 487-493.

Hökfelt, T., R. Elde, O. Johannson, L. Terenius, and L. Stein (1977) The distribution of enkephalin-immunoreactive cell bodies in the rat nervous system. Neurosci. Lett. 5: 25-31.

Hooper, N. M., A. J. Turner, and A. J. Kenny (1985) The metabolism of neuropeptides. Neurokinin A (substance K) is a substrate for endopeptidase 24.11 but not peptidyl dipeptidase A. Biochem. J. 231: 357-361.

Kerr, M. A., and A. J. Kenny (1974) The purification and specificity of a neutral endopeptidase from rabbit kidney brush border. Biochem. J. $137: 477-488$.

Koelle, G. B., and J. S. Friedenwald (1949) A histochemical method for localizing cholinesterase activity. Proc. Soc. Exp. Biol. 70: 617622.

Köhler, C., and R. Schwarcz (1983) Comparison of ibotenate and kainate neurotoxicity in rat brain: A histological study. Neuroscience 8: 819-835.

Malfroy, B., and J.-C. Schwartz (1982) Properties of "enkephalinase" from rat kidney: Comparison of dipeptidyl-carboxypeptidase and endopeptidase activities. Biochem. Biophys. Res. Commun. 106: 276285.

Malfroy, B., J. P. Swerts, A. Guyon, B. P. Roques, and J.-C. Schwartz (1978) High affinity enkephalin-degrading peptidase in brain is increased after morphine. Nature 276: 523-526.

Matsas, R., I. S. Fulcher, A. J. Kenny, and A. J. Turner (1983) Substance $P$ and [Leu]enkephalin are hydrolyzed by an enzyme in pig caudate synaptic membranes that is identical with the endopeptidase of kidney microvilli. Proc. Natl. Acad. Sci. USA 80: 3111-3115.

Matsas, R., M. Rattray, A. J. Kenny, and A. J. Turner (1985) The metabolism of neuropeptides. Endopeptidase-24.11 in human synaptic membrane preparations hydrolyses substance P. Biochem. J. 228: $487-492$

Matsas, R., A. J. Kenny, and A. J. Turner (1986) An immunohistochemical study of endopeptidase-24.11 ("enkephalinase") in the pig nervous system. Neuroscience 18: 991-1012.

McGinty, J. F., D. Van der Kooy, and F. E. Bloom (1985) Distribution and morphology of opioid peptide immunoreactive neurons in the cerebral cortex of rats. J. Neurosci. 4: 1104-1114.

McKelvy, J. F., and S. Blumberg (1986) Inactivation and metabolism of neuropeptides. Annu. Rev. Neurosci. 9: 415-434.

Monaghan, D. T., and C. W. Cotman (1985) Distribution of $N$-methylD-aspartate sensitive ${ }^{\mathrm{L}}-\left[{ }^{3} \mathrm{H}\right]$ glutamate-binding sites in rat brain. $\mathrm{J}$. Neurosci. 5: 2909-2919.

Orlowski, M., and S. Wilk (1981) Purification and specificity of a membrane-bound metalloendopeptidase from bovine pituitaries. Biochemistry 20: 4942-4950.

Palkovits, M., J. Epelbaum, and C. Gros (1981) Met-enkephalin concentrations in individual brain nuclei of ansa lenticularis and stria terminalis transected rats. Brain Res. 216: 203-209.

Patey, G., S. A. De la Baume, J.-C. Schwartz, C. Gros, B. P. Roques, M. C. Fournie-Zaluski, and E. Soroca-Lucas (1981) Selective protection of methionine enkephalin released from brain slices by enkephalinase inhibition. Science 212: 1153-1155.

Paxinos, G., and C. Watson (1986) The Rat Brain in Stereotaxic Coordinates, 2nd ed., Academic, Worth Ryde, Australia.
Petrusz, P., I. Merchenthaler, and J. L. Maderdrut (1985) Distribution of enkephalin-containing neurons in the central nervous system. In Handbook of Chemical Neuroanatomy, Vol. 4, A. Björklund and T. Hökfelt, eds., pp. 273-334, Elsevier, Amsterdam.

Pickel, V. M., K. K. Sumal, S. C. Beckley, R. J. Miller, and D. J. Reis (1980) Immunocytochemical localization of enkephalin in the neostriatum of rat brain: A light and electron microscopic study. J. Comp. Neurol. 189: 721-740.

Pierart, M. E., T. Najdovski, T. E. Appelboom, and M. M. DeschodtLanckman (1988) Effect of human endopeptidase 24.11 ("enkephalinase") on IL-1-induced thymocyte proliferation assay. J. Immunol. 140: 3808-3811.

Pollard, H., C. Llorens-Cortes, J.-V. Couraud, P. Ronco, P. Verrous, and J.-C. Schwartz (1987a) Enkephalinase (EC 3.4.24.11) is highly localized to a striatonigral pathway in rat brain. Neurosci. Lett. 77 : 267-271.

Pollard, H., S. De la Baume, M.-L. Bouthenet, J.-C. Schwartz, P. Ronco, and $P$. Verroust (1987b) Characterisation of two probes for the localisation of enkephalinase in rat brain: $\left[{ }^{3} \mathrm{H}\right]$ thiorphan and a ${ }^{125} \mathrm{I}-$ labeled monoclonal antibody. Eur. J. Pharmacol. 133: 155-164.

Roques, B. P., M. C. Fournie-Zaluski, E. Soroca, J. M. Lecomte, B. Malfroy, C. Llorens, and J.-C. Schwartz (1980) The enkephalinase inhibitor thiorphan shows antinociceptive activity in mice. Nature 288: 286-288

Sar, M., W. E. Stumpf, R. J. Miller, K-J. Chang, and P. Cuatrecasas (1978) Immunohistochemical localization of enkephalin in rat brain and spinal cord. J. Comp. Neurol. 182: 17-38.

Schmued, L. S., L. W. Swanson, and P. E. Sawchenko (1982) Some fluorescent counterstains for neuroanatomical studies. J. Histochem. Cytochem. 30: 123-128.

Simantov, R., M. J. Kuhar, G. R. Uhl, and S. H. Snyder (1977) Opioid peptide enkephalin: Immunohistochemical mapping in rat central nervous system. Proc. Natl. Acad. Sci. USA 74: 2167-2171.

Smith, R. E. (1983) Contributions of histochemistry to the development of the proteolytic enzyme detection system in diagnostic medicine. J. Histochem. Cytochem. 31: 199-219.

Solhonne, B., C. Gros, H. Pollard, and J.-C. Schwartz (1987) Major localization of aminopeptidase $M$ in rat brain microvessels. Neuroscience 22: 225-232.

Somogyi, P., J. V. Priestly, A. C. Cuello, A. D. Smith, and H. Takagi (1982) Synaptic connections of enkephalin-immunoreactive nerve terminals in the neostriatum: A correlated light and electron microscopic study. J. Neurocytol. 11: 779-807.

Sternberger, L. (1979) Immunohistochemistry, 2nd ed., Wiley, New York.

Stewart, G. R., M. Price, J. W. Olney, B. K. Hartman, and C. Cozzari (1986) $\mathrm{N}$-methylaspartate: An effective tool for lesioning basal forebrain cholinergic neurons of the rat. Brain Res. 369: 377-382

Supattapone, S., S. M. Strittmatter, L. D. Fricker, and S. H. Snyder (1988) Characterization of a neutral, divalent cation-sensitive endopeptidase: A possible role in neuropeptide processing. Mol. Brain Res. 3: 173-182.

Turner, A. J., R. Matsas, and A. J. Kenny (1985) Are there neuropeptide-specific peptidases? Biochem. Pharmacol. 34: 1347-1356.

Uhl, G. R., R. R. Goodman, M. J. Kuhar, S. R. Childers, and S. H. Synder (1979) Immunohistochemical mapping of enkephalin-containing cell bodies, fibers and nerve terminals in the brain stem of the rat. Brain Res. 166: 75-94.

Waksman, G., E. Hamel, M. C. Fournie-Zaluski, and B. P. Roques (1986) Autoradiographic comparison of the distribution of the neutral endopeptidase enkephalinase and of the mu and delta opioid receptors in rat brain. Proc. Natl. Acad. Sci. USA 83: 1523-1527.

Waksman, G., E. Hamel, P. Delay-Goyet, and B. P. Roques (1987) Neutral endopeptidase-24.11, $\mu$ and $\delta$ opioid-receptors after selective brain lesions: An autoradiographic study. Brain Res. 436: 205-216.

Wamsley, J. K., W. S. Young III, and M. J. Kuhar (1980) Immunohistochemical localization of enkephalin in rat forebrain. Brain Res. 190: 153-154.

Yaksh, T. L., and G. J. Harty (1982) Effects of thiorphan on the antinociceptive actions of intrathecal $\left[\mathrm{D}-\mathrm{Ala}^{2}, \mathrm{Met}^{5}\right]$ enkephalin. Eur. J. Pharmacol. 79: 293-300.

Zuzel, K. A., C. Rose, and J.-C. Schwartz (1985) Assessment of the role of enkephalinase in cholecystokinin inactivation. Neuroscience 15: $149-158$ 